\title{
Nanodiamonds for bioapplications, recent developments
}

Nicolas Bondon, ${ }^{* a c}$ Laurence Raehm, ${ }^{a}$ Clarence Charnay, ${ }^{a}$ Rabah Boukherroub ${ }^{b}$ and Jean-Olivier Durand $^{\text {a }}$

${ }^{*}$ Corresponding authors

${ }^{a}$ Institut Charles Gerhardt Montpellier, UMR 5253, CNRS-UM-ENSCM, Université de Montpellier, Place Eugène Bataillon 34095, Montpellier cedex 05, France

E-mail: nicolas.bondon@umontpellier.fr

${ }^{b}$ Univ. Lille, CNRS, Centrale Lille, Univ. Polytechnique Hauts-de-France, UMR 8520, IEMN, F-59000 Lille, France

${ }^{\mathrm{C}}$ Laboratoire Cogitamus, France

\begin{abstract}
The world of biomedical research is in constant evolution, requiring more and more conditions and norms through pre-clinic and clinic studies. Nanodiamonds (NDs) with exceptional optical, thermal and mechanical properties emerged on the global scientific scene and recently gained more attention in biomedicine and bioanalysis fields. Many problematics have been deliberated to better understand their in vitro and in vivo efficiency and compatibility. Light was shed on their synthesis, modification and purification steps, as well as particle size and surface properties in order to find the most suitable operating conditions. In this review, we present the latest advances of NDs use in bioapplications. A large variety of subjects including anticancer and antimicrobial systems, wound healing and tissue engineering management tools, but also bioimaging and labeling probes are tackled. The key information resulting from these recent works were evidenced to make an overview of the potential features of NDs, with a special look on emerging therapeutic and diagnosis combinations.
\end{abstract}

\section{Introduction}

Bioapplications need many prerequisites to be safe and efficient. The use of nanoparticles (NPs) has gained more and more attention due to their small size and high surface to volume ratio, but there are many concerns about their harmfulness for the living. Among NPs, nanodiamonds compatibility in living organisms, from administration to clearance, is intensely watched. According to several in vivo studies, NDs are well-tolerated and non-toxic. ${ }^{1}$ Moreover, in the midst of carbon-based nanomaterials, NDs seem to be the most biocompatible species of their family. This fundamental property is associated with high specific surface area, inert carbon core with various impurities and defects and tunable surface chemistry. Other characteristics of ND-based materials, such as surface zeta potential, tissue penetration, dispersibility and accessibility, can be modulated for optimal use in biological media. ${ }^{2}$ Therefore, biological parameters such as aggregation, metabolism, internalization and toxicity can be controlled, providing better risk-benefit ratio towards therapeutic and bioimaging systems. ${ }^{3}$

NDs are classified into different categories depending on their bare size and synthesis process. Detonation nanodiamonds (DNDs) basically exhibit monodisperse size close to $5 \mathrm{~nm} .^{1,4,5}$ They are manufactured by shocks with trinitrotoluene-like explosives and hexogen, where graphite is converted in tiny little gems in a bottom-up approach, prior to purification and washing phases. ${ }^{6}$ Fluorescent nanodiamonds (FNDs) with wider size distribution than DNDs, are principally shaped from expensive high pressure and high temperature (HPHT) diamond and grinding procedure, which confer them very stable defects. Their intrinsic fluorescence, originating from nitrogen-vacancy $(\mathrm{N}-\mathrm{V})$ color centers, and their good biostability render them ideal for tracking and imaging upon light excitation. ${ }^{7}$ Nano-sized diamonds can also be obtained by chemical vapor deposition or pulsed laser ablation in liquids, but these processes are less common and expensive. ${ }^{8-10}$ 
Before their use in formulations for bioapplications, NDs are purified to selectively remove impurities (non-diamond carbons, metals, oxides and other particles) to control their surface chemistry. The restrictive aggregation effect of bare NDs, which is one frequently discussed issue, can be solved by different strategies governed by physical principles or chemical modifications. The former gathers milling, sonic disintegration, and annealing techniques, while the latter refers to surface modification by oxygenated functions or small molecules to bring stability to the final materials. ${ }^{3}$

DNDs are commonly chosen in anticancer drug delivery systems owing to their low cost, chemical inertia and ability to overcome multidrug resistance. ${ }^{11}$ In addition, their high specific surface area and small monodisperse size allow higher release rates and good therapeutic in vivo efficacy via targeting molecules such as polymers, peptides and liposomes. ${ }^{1,5,6}$ They show good relevancy as topical antineoplastic drug delivery transporters, cancer stem cells eradication enhancers and chemoresistance suppressors. ${ }^{3}$ Their alterable surface and biocompatibility render them suitable drug carriers protecting against protein adhesion and immune responses, leading to longer circulation time in the body and better selectivity for the tumor sites. ${ }^{1}$

NDs have been adapted for use with several drugs, demonstrating positive input and lower side effects. For instance, studies of materials loaded with doxorubicin (DOX) displayed interesting tumor growth inhibition, prolonged release in the cytoplasm or increased drug uptake in cancer cells nucleus. ${ }^{3,12,13}$ These fluorescent gems can also be beneficial in photodynamic therapy (PDT), generally associated with active photosensitizers whose activity relies on phosphorescence phenomenon. By non-radiative intersystem crossing, these materials can generate reactive oxygen species (ROS) by electron or energy transfer during electronic transitions from excited to ground states..$^{14}$ Additionally, there is potential in photothermal therapy (PTT), by which light is converted into heat to wipe out malignant cells. ${ }^{5}$

Otherwise, NDs have considerable potential as bioimaging probes due to their fluorescence properties, generally associated to ND intrinsic impurities ( $\mathrm{N}-\mathrm{V}$ and silica-vacancy color centers). Among the different ranges, FNDs, generally bigger in size than DNDs, can be fluorescent markers to monitor uptake efficiency, uptake pathways, and intracellular behavior. ${ }^{15}$ Fluorescence imaging is usually facing two issues: autofluorescence of tissues and light absorption by biomolecules in UV-vis domain, leading to photobleaching and poor brightness level. Intrinsic stable defects fluorescence of NDs is ideal for bio-tracking, as it displays high lifetime (20-30 ns) contrary to biomolecules autofluorescence that is usually of 1-4 ns, providing high contrast imaging. ${ }^{6}$ Interestingly, ND N-V centers are emitting from 600 to $800 \mathrm{~nm}$. In these conditions, there is no intense photon absorption by body biomolecules, thus, no signal perturbation. ${ }^{5}$ Autofluorescence photobleaching and bad penetration in the tissues are avoided in near-infrared (NIR) conditions.

Furthermore, covalent and non-covalent attachment of emitting fluorophores enhances imaging quality. ${ }^{15}$ Great fluorescence can be achieved by the use of fluorophores, such as fluorescein, Hoechst blue, rare-earth (RE) elements and quantum dots (QDs), but it has been reported that FNDs possess the advantage to show better biocompatibility. ${ }^{7}$ Hence, two strategies are considered for their use in bioimaging and labeling: NDs carrying chromophores for a synergistic action or NDs as a unique fluorescence source. Unfortunately, FNDs bioapplications are limited due to their big size compared to classic fluorescent molecules $(<20 \mathrm{~nm}){ }^{1}$ The use of detonated NDs would be a good alternative as they have better biocompatibility and versatility, but this will require the enhancement of intrinsic $\mathrm{N}$ $\checkmark$ distribution and quantity.

NDs have proven their effectiveness for a wide range of diagnosis techniques. In photoacoustic microscopy, the great optical absorbance of NDs can render them suitable CAs to enhance signals' sensitivity. ${ }^{15}$ This parameter is also a crucial requirement to perform magnetic resonance imaging (MRI) and a controlled creation of paramagnetic N-V defects could make them outstanding contrast 
agents (CAs) for MRI based on T1 relaxation time. Additionally, they can also be used as carriers to enhance the biocompatibility of classic T1 based CAs. ${ }^{16}$ Owing to their optical properties, NDs are naturally good probes for Raman imaging in NIR II domain as they display a strong peak at $1332 \mathrm{~cm}^{-1}$, which is far from living cells' signals $\left(2800-3200 \mathrm{~cm}^{-1}\right)$, allowing an easy monitoring without signal perturbation. Moreover, as Raman spectroscopy made great progress for 4D temporal and spatial resolution and 3D imaging, ND-based materials could enable the access to further information by internalizing into the cells. ${ }^{5}$ ND-based systems could also be well-suited to answer the challenges related to emerging bioimaging techniques. Super-resolution imaging such as stimulated emission depletion (STED) microscopy can be performed with red or green fluorescent NDs, demonstrating impressive resolution of about $10 \mathrm{~nm}$. In STED optical analyses, there is a need for high photostability that could be mastered by FNDs as they can be internalized in living cells. ${ }^{16,17}$ NDs use in correlative light-electron microscopy is also a very stimulating challenge for the coming years as electronic and fluorescence properties, coming from defects and surface functionalization, can be combined ${ }^{16}$ More recently, hyperpolarized MRI using dynamic nuclear polarization has emerged as a promising technique even if it presents some drawbacks like the need for cryogenic temperature and long-time analyses. ${ }^{18}$ Irradiation at room temperature of ${ }^{13} \mathrm{C}$ nuclear spins from FNDs led to upraising T1 signal intensities. ${ }^{19,20}$

There is also a renewed interest for elaborating new strategies against infectious diseases causing chronic inflammation and tissue damage, due to the growing antimicrobial resistance phenomenon, characterized by drug-resistant bacteria. ${ }^{21-23}$ Some alternatives to antibiotics have already been tested, and many of them consisting of NPs-polymers composites searching for the best anti-adhesive properties against bacteria and their protective barriers, the so-called biofilms. ${ }^{24-28}$ Nanodiamonds are gradually tested as potent efficient tools to fight infections, because they can hold optical transparency, fluorescence behavior, and tunable surfaces. ${ }^{29-34}$ Like in the majority of bioapplications, biocompatibility and poor toxicity are compelling prerequisites. ${ }^{35}$ Thus, with judicious designs, one can easily imagine both passive and active antibacterial roles for these probes.

Previous in vitro studies of different NDs antimicrobial efficacy underlined better killing effects depending on purification process, annealing and functional groups, notably in the case of ND negatively-charged surface. Strains nature is also a major parameter according to discordant conclusions with ND-NH ${ }_{2}$ and ND-mannose grafting, probably due to the size, morphology, and above all to the biological composition of the bacteria membranes. ${ }^{36} \mathrm{~A}$ better understanding of microbial damaging mechanisms is urgent, including immune system behavior in facing adhesion and growth processes. For example, culture media composition can influence antimicrobial activities as expressed in recent in vitro assays on E. coli using two different NDs in Luria-Bertani (LB) or Mueller-Hinton (MH) nutritious medium. The nanomaterials seemed more effective in LB media compared to $\mathrm{MH}$ due to a poor $\mathrm{Ca}^{2+}$ and $\mathrm{Mg}^{2+}$ content, more suitable for the generation of oxidative stress. ${ }^{37}$ In another study, carboxylated NDs in LB caused partial membrane disruption and cell death. ${ }^{38}$ Moreover, glycanconjugated NDs borne strong affinity to type I FimH fimbriae from E. coli lectins, with good ability in restraining metabolic pathways, inducing cell death and potential biofilm destruction. ${ }^{15,36}$ Research about infections also require to pay attention to biofilms, as they can reproduce fast and gather, in a complex matrix, huge quantities of microbes. Thus, inhibiting biofilm growth at its early stage is decisive and the properties of antimicrobial agents can make a clear difference to solve this problem. ${ }^{36}$

Nanodiamonds could lead to vast findings in many other medicinal applications. In skin relative diseases, for enhanced transport, delivery and efficacy of drugs, hydrophilicity tuning and high dispersibility of functionalized NDs are appealing factors. Therefore, NDs can reinforce both the quality and the activity of classical composites applied for wound management, tissue engineering and various 
diseases closely linked to the immune system behavior. ${ }^{2}$ These hybrid materials generally include biopolymers such as polyethylene glycol, chitosan and bacterial cellulose, with good chemical structures and properties for wound covering designs and skin pathologies applications. ${ }^{7}$ Besides, several drug and gene delivery experiments have been performed by using ND-based formulations promoting faster repair process through a large variety of favorable effects like protection against instability and functionalized surfaces for a better penetration. ${ }^{2}$ One recurrent strategy is to enhance growing factors distribution to the wound site. ${ }^{39}$

In this review, we selected the most recent articles where NDs potential is explored in a perspective of medicinal use. We divided our review by application type, from cancer research to bioimaging and biolabeling, covering studies dealing with other diseases. We presented the key information about materials synthesis, modification and preparation, toxicity and safety, but also the main results with or without ND moieties (Table 1). Our goal is to provide a summary of NDs advantages and input, when possible, and to shed light on rising strategies for improved therapeutic balance and upgraded diagnosis.

\section{Nanodiamonds in cancer therapy research}

One of the biggest topics in current cancer therapy research is building nanomaterials with several features. Whether they have a good ability to enhance chemosensitivity, a prolonged delivery with high stability and selectivity levels or an active role in phototherapy due to their fluorescence, nanodiamonds can be efficient tools in lowering drug side effects and enhancing the theranostic outcome. $^{3}$

In this context, there is still room for improving cellular uptake pathways. Sigaeva's group presented an interesting strategy where $120 \mathrm{~nm}$ FNDs were stabilized by dilution in high glucose Dulbecco's Modified Eagle Medium (DMEM) containing 10\% of fetal bovine serum (FBS). By testing different methodologies, they demonstrated that internalized FNDs amount in HT-29 colon cancer cells was considerably dependent of the taken direction. Uptake was much more efficient when FNDs were guided to enter by the basolateral side of plasma membrane. Moreover, when FNDs were incorporated from the apical border, impressive internalization rates were obtained on gathered HT-29 cells, but these remarkable results were mainly due to an initial trypsin-ethylenediaminetetraacetic acid (EDTA) treatment step performed until particles were well spread. Trypsin, a well-known enzyme, can improve dispersibility by bound cleavage between cells and can also affect cell surface (composition, surface area, etc.) for easier penetration. By both strategies, about $95 \%$ of colon carcinoma cells contained FNDs for a concentration of $5 \mu \mathrm{g} \cdot \mathrm{mL}^{-1}$, whereas it was $50 \%$ when directed to the apical side without enzymatic treatment. ${ }^{40}$ This research is notable for not entailing any FNDs surface functionalization and its results could be taken into account in future theranostic applications.

\subsection{Cellular uptake and anticancer drug delivery studies}

Like many nanoparticles, nano-sized diamonds can be powerful carriers of antineoplastic drugs, providing higher selectivity towards tumor cells due to their protective capacity. In their report, Yu et al. developed a sonication method to encapsulate camptothecin (CPT) anticancer agent in alkyl-amine modified NDs. Three different alkyl-amine molecules were grafted to purified DNDs suspended in water (ND-ori, Fig.1) through condensation between amine moiety and surface carboxyl functions, using water soluble carbodiimide hydrochloride (WSC) carbodiimide linkage agent in a slightly acidic 2-(N-morpholino)ethanesulfonic acid (MES) buffer. Then, these particles self-assembled while being sonicated. The resulting scaffolds were ideal for CPT transport as they gave high biocompatibility results in vitro and in vivo, but also huge killing effect compared to classic CPT-polyethylene glycol 


\begin{tabular}{|c|c|c|c|c|c|c|}
\hline $\begin{array}{l}\text { ND type/purification } \\
\text { method/impurities } \\
\text { content/coating }\end{array}$ & Global system & $\begin{array}{l}\text { Average size } \\
\text { (technique)/ } \\
\text { others }\end{array}$ & Biological model & Parameter assessed & Conclusions & References \\
\hline $\begin{array}{l}120 \mathrm{~nm} \text { HPHT FNDs, } \\
\text { liquid and air oxid., } \\
\text { imp.: n.a. }\end{array}$ & $\begin{array}{l}\text { FNDs in various } \\
\text { media }\end{array}$ & $120 \mathrm{~nm}$ (n.a.) & $\begin{array}{l}\text { HT-29 colon } \\
\text { cancer cells }\end{array}$ & $\begin{array}{l}\text { Cellular uptake rate } \\
\text { (among direction } \\
\text { and pre-treatment) }\end{array}$ & $\begin{array}{l}5 \mu \mathrm{g} \cdot \mathrm{mL}^{-1} \mathrm{NDs} \text { (from apical side }+\mathrm{T} \text {-EDTA pre- } \\
\text { treatment or from basolateral side (no treatment)): } \\
95 \% \text { cells contain NDs }\end{array}$ & 40 \\
\hline \multirow[t]{2}{*}{$\begin{array}{l}\text { 4-5 nm DNDs, liquid } \\
\text { oxid., imp.: n.a. }\end{array}$} & CPT@ND-SPs & $\begin{array}{l}20-100 \mathrm{~nm}(\mathrm{DLS}) \\
\text { no CPT }\end{array}$ & $\begin{array}{l}\text { Bone } \\
\text { osteosarcoma cells }\end{array}$ & Cell viability & $\begin{array}{l}20 \mu \mathrm{g} \cdot \mathrm{mL}^{-1} \text { system: } 90 \% \text { killing, other CPT-complexes } \\
\text { gave up to } 50 \% \text { killing }\end{array}$ & 41 \\
\hline & & & $\begin{array}{l}\text { HT- } 29 \text { colon tumor } \\
\text { xenografts in mice }\end{array}$ & Tumor volumes & $\begin{array}{l}3 \mathrm{mg} \cdot \mathrm{kg}^{-1} \mathrm{CPT} \text { in } 56 \mathrm{mg} \cdot \mathrm{kg}^{-1} \mathrm{ND}-\mathrm{SPs}: 16 \text { days after } \\
\text { treatment, about } 40 \% \text { tumor size reduction vs. PBS } \\
\text { control }\end{array}$ & \\
\hline $\begin{array}{l}\text { 2-10 nm DNDs, imp.: } \\
\text { n.a., used as-received }\end{array}$ & ND-PEG-DOX & $\begin{array}{l}979.08 \pm 55 \mathrm{~nm} \\
\text { (DLS in water) }\end{array}$ & $\begin{array}{l}\text { HepG2 liver cancer } \\
\text { cells }\end{array}$ & Cell viability & $\begin{array}{l}200 \mu \mathrm{g} \cdot \mathrm{mL}^{-1} \text { free DOX or system (lower DOX rate): } \\
\text { about } 75 \% \text { killing effect }\end{array}$ & 42 \\
\hline \multirow{3}{*}{$\begin{array}{l}100 \mathrm{~nm} \text { ND-PEG } \\
\text { powders (previously } \\
\text { carboxylated), liquid } \\
\text { oxid., imp.: n.a. }\end{array}$} & $\begin{array}{l}\text { ND-PEG-GLY- } \\
\text { DOX }\end{array}$ & $\begin{array}{l}293.6 \pm 0.8 \mathrm{~nm} \\
\text { (DLS in water) }\end{array}$ & $\begin{array}{l}\text { HepG2, HeLa, } \\
\text { MCF-7 cancer cells }\end{array}$ & Cell viability & Inhibition of tumor proliferation, high toxicity levels & 43,44 \\
\hline & & & $\begin{array}{l}\text { HepG2 tumor } \\
\text { xenografts in mice }\end{array}$ & Body weight & $\begin{array}{l}\text { No weight loss after } 25 \text { days compared to } 20 \% \\
\text { change with GLY-DOX }\end{array}$ & \\
\hline & & & MCF-7 cancer cells & $\begin{array}{l}\text { Cell tracking and } \\
\text { fluorescence }\end{array}$ & $\begin{array}{l}\text { GLY-DOX released } 1 \mathrm{~h} \text { after injection (green } \\
\text { fluorescence). Good photostability compared to free } \\
\text { GLY-DOX }\end{array}$ & \\
\hline \multirow[t]{2}{*}{$\begin{array}{l}20-50 \text { nm ND-PEG, } \\
\text { imp.: } \text { n.a., used as- } \\
\text { received }\end{array}$} & ND-PEG-DOX & $\begin{array}{l}962 \pm 140 \mathrm{~nm}(\mathrm{DLS} \\
\text { in PBS) }\end{array}$ & $\begin{array}{l}\text { BxPC3 pancreatic } \\
\text { cancer 3D } \\
\text { spheroids }\end{array}$ & Cell viability & $\begin{array}{l}60 \mu \mathrm{g} \cdot \mathrm{mL}^{-1} \text { system }\left(10 \mu \mathrm{g} \cdot \mathrm{mL}^{-1} \mathrm{DOX}\right): 90 \% \text { killing (free } \\
\text { DOX: about } 50 \% \text { ) }\end{array}$ & 45 \\
\hline & & & $\begin{array}{l}6741 \text { pancreatic } \\
\text { tumor xenografts } \\
\text { in NSG mice }\end{array}$ & Tumor volumes & $\begin{array}{l}\text { After } 3 \text { weeks treatments ( } 2 \text { injections per week of } 10 \\
\text { mg.kg-1 }): 4 \text { times lower volumes vs. free DOX } \\
\text { equivalent }\end{array}$ & \\
\hline $\begin{array}{l}\text { 2-8.3 nm HOOC-DNDs } \\
\text { and HPHT NDs, } \\
\text { thermally annealed, } \\
\text { imp.: n.a. }\end{array}$ & ND-TTA:RE-DOX & $\begin{array}{l}\text { 100-200 nm (DLS), } \\
\text { no DOX }\end{array}$ & $\begin{array}{l}\text { SGC-7901 gastric } \\
\text { cancer cells }\end{array}$ & $\begin{array}{l}\text { Cell viability, drug } \\
\text { release, } \\
\text { fluorescence } \\
\text { properties }\end{array}$ & $\begin{array}{l}1 \text { to } 16 \mu \mathrm{g} \cdot \mathrm{mL}^{-1} \text { : similar toxicity than free DOX for } \\
\text { equivalent rate. Prolonged and slow release vs. free } \\
\text { DOX control (for } 24 \mathrm{~h} \text { ). Sustainable fluorescence and } \\
\text { high stability for cell imaging }\end{array}$ & 46 \\
\hline
\end{tabular}




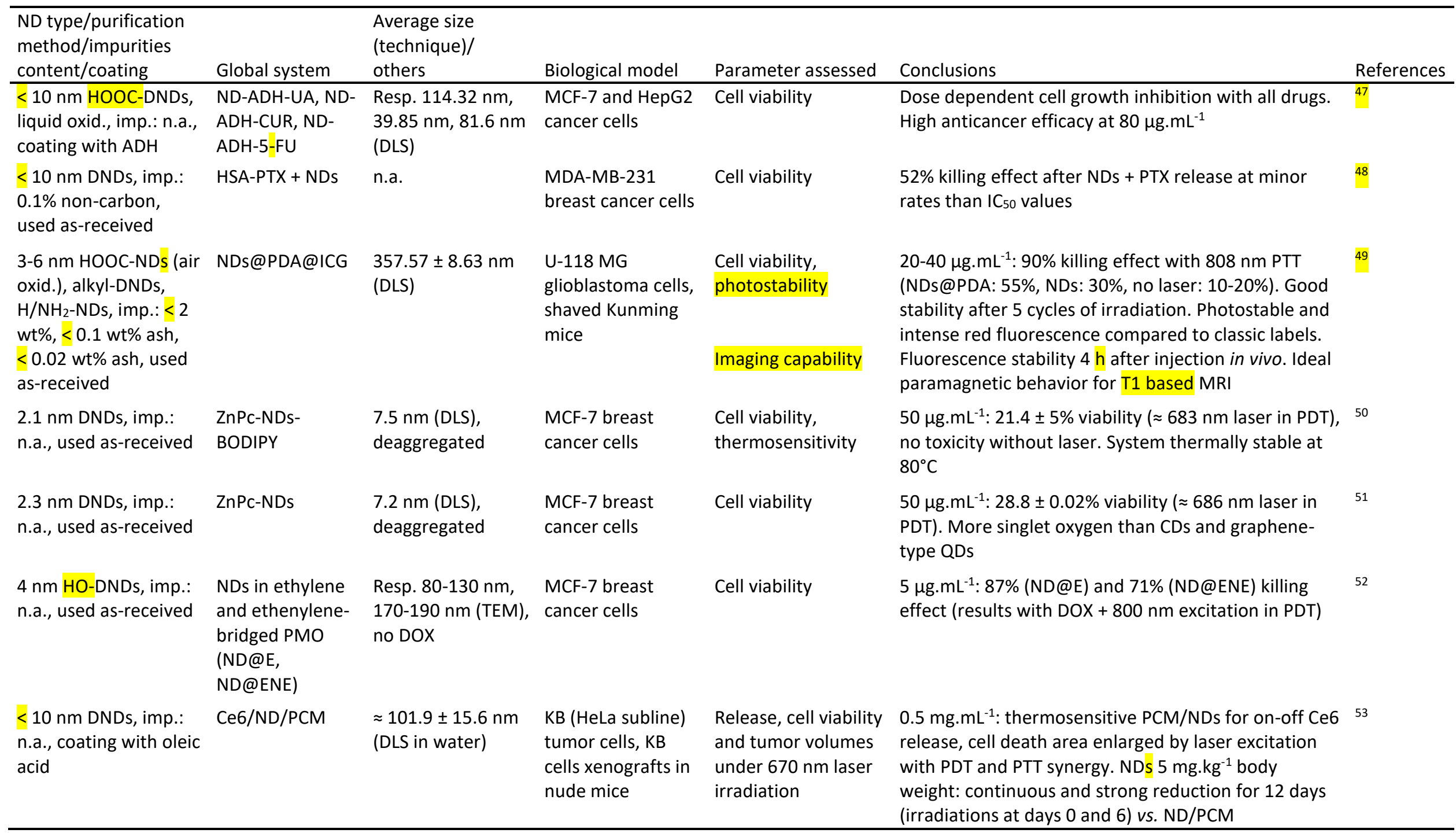




\begin{tabular}{|c|c|c|c|c|c|c|}
\hline $\begin{array}{l}\text { ND type/purification } \\
\text { method/impurities } \\
\text { content/coating }\end{array}$ & Global system & $\begin{array}{l}\text { Average size } \\
\text { (technique)/ } \\
\text { others }\end{array}$ & Biological model & Parameter assessed & Conclusions & References \\
\hline $\begin{array}{l}\text { 2-10 nm HO-DNDs, } \\
\text { imp.: n.a., used as- } \\
\text { received }\end{array}$ & $\begin{array}{l}\text { ND-AIE dye- } \\
\text { polymer }\end{array}$ & $\begin{array}{l}118 \pm 45.9 \mathrm{~nm} \\
\text { (DLS in PBS) }\end{array}$ & L929 mouse cells & $\begin{array}{l}\text { Cell viability, } \\
\text { fluorescence } \\
\text { properties }\end{array}$ & $\begin{array}{l}120 \mu \mathrm{g} \cdot \mathrm{mL}^{-1}: 85 \% \text { viability after } 48 \mathrm{~h} \text {. Good uptake } \\
\text { and strong orange fluorescence for cell imaging }\end{array}$ & 54 \\
\hline $\begin{array}{l}\text { 3-10 nm DNDs, } 50 \text { and } \\
100 \mathrm{~nm} \text { HPHT FNDs, } \\
\text { liquid oxid., imp.: } \text { n.a. }\end{array}$ & HOOC-NDs & $\begin{array}{l}\text { Resp. } 258 \pm 60 \mathrm{~nm}, \\
118 \pm 33 \mathrm{~nm}, 150 \pm \\
25 \mathrm{~nm} \text { (DLS) }\end{array}$ & Murine skin models & $\begin{array}{l}\text { Multimodal } \\
\text { imaging }\end{array}$ & $\begin{array}{l}100 \mathrm{~nm} \text { FNDs globally more suitable. Tissues } \\
\text { autofluorescence superior to NDs fluorescence at } 800 \\
\mathrm{~nm}\end{array}$ & 55 \\
\hline $\begin{array}{l}5 \mathrm{~nm} \text { CD-DNDs } \\
\text { (surface } \mathrm{COOH} \text { ), liquid } \\
\text { oxid., imp.: } 0.5 \mathrm{wt} \%\end{array}$ & CD-DNDs & $\begin{array}{l}\text { 4-5 } \mathrm{nm} \text { (DLS), } \\
\text { deaggregated }\end{array}$ & $\begin{array}{l}\text { MDA-MB-231 } \\
\text { breast cancer cells } \\
\text { Zebrafish embryos }\end{array}$ & $\begin{array}{l}\text { Fluorescence } \\
\text { properties } \\
\text { Biocompatibility }\end{array}$ & $\begin{array}{l}488 \mathrm{~nm} \text { argon laser excitation: good fluorescence } \\
\text { after internalization } \\
\text { Good compatibility in vivo but need to overcome } \\
\text { particles clustering tendency }\end{array}$ & 56 \\
\hline $\begin{array}{l}25 \mathrm{~nm} \text { HPHT NDs, } \\
\text { liquid oxid., imp.: } \\
1.75 \% \text { non-diamond }\end{array}$ & $\begin{array}{l}\mathrm{Fe}_{3} \mathrm{O}_{4}-\mathrm{ND}-\mathrm{PEI}- \\
\mathrm{AMOX}\end{array}$ & $350 \mathrm{~nm}$ (DLS) & $\begin{array}{l}\mathrm{pH} 4 \text { citrate buffer } \\
\text { solution }\end{array}$ & Drug release & $\begin{array}{l}\text { Prolonged release }(180 \mathrm{~h}) \text { with NDs, lower without } \\
(24 \mathrm{~h}) . \text { More drug release rate in acidic conditions } \\
\text { and at } 37^{\circ} \mathrm{C}\end{array}$ & 57,58 \\
\hline $\begin{array}{l}100 \mathrm{~nm} \text { HOOC-NDs, air } \\
\text { and liquid oxid., imp.: } \\
\text { n.a., PA coated }\end{array}$ & Ag-ND@BSA & $\begin{array}{l}120 \pm 30 \mathrm{~nm} \text { (DLS } \\
\text { in water) }\end{array}$ & E. coli strain & Cell viability & $\begin{array}{l}250 \mu \mathrm{g} \cdot \mathrm{mL}^{-1} \mathrm{Ag} \mathrm{NPs} \text { : strong bactericidal effect for } 36 \\
\text { days }\left(\mathrm{CC}_{50}>>500 \mu \mathrm{\mu g} \cdot \mathrm{mL}^{-1}\right) \text {. Low toxicity on healthy } \\
\text { human cells }\end{array}$ & 59 \\
\hline $\begin{array}{l}3-5 \mathrm{~nm} \text { HOOC-DNDs, } \\
\text { imp.: n.a., used as- } \\
\text { received }\end{array}$ & HOOC-DNDs & $\begin{array}{l}\approx 5 \mathrm{~nm} \text { (DLS), } \\
\text { deaggregated }\end{array}$ & $\begin{array}{l}\text { MC3T3-E1 bone } \\
\text { cells } \\
\text { S. aureus or E. coli } \\
\text { strain }\end{array}$ & $\begin{array}{l}\text { Tribological effect } \\
\text { Bacteria growth }\end{array}$ & $\begin{array}{l}450 \mu \mathrm{g} \cdot \mathrm{mL}^{-1} \mathrm{NDs} \text { : friction minimized and reduced } \\
\text { polyethylene surfaces wear } \\
31-1000 \mu \mathrm{g} \cdot \mathrm{mL}^{-1} \mathrm{NDs} \text { : reduced } S \text {. aureus development } \\
\text { but no significant effect against } E \text {. coli development }\end{array}$ & 60 \\
\hline $\begin{array}{l}\text { 4-6 } \mathrm{nm} \text { DNDs, imp.: } \\
\text { n.a., used as-received }\end{array}$ & PMMA-ND & $\begin{array}{l}\text { Average roughness } \\
<200 \mathrm{~nm} \text { (AFM) }\end{array}$ & Candida Albicans & $\begin{array}{l}\text { Fungi resistance, } \\
\text { mechanical } \\
\text { properties }\end{array}$ & $\begin{array}{l}0.1-0.5 \text { wt\% NDs: reduced viability and biofilm } \\
\text { formation vs. ZrO NPs and vs. control. Higher flexural } \\
\text { strength and elastic modulus }\end{array}$ & 61 \\
\hline $\begin{array}{l}\text { 3-5 nm HOOC-DNDs, } \\
\text { thermally annealed, } \\
\text { imp.: n.a. }\end{array}$ & $\begin{array}{l}\text { ND-doped DLC } \\
\text { films (deposited } \\
\text { on alloy surface) }\end{array}$ & $\begin{array}{l}1626 \mathrm{~nm}(\mathrm{n} . \mathrm{a}) \\
\text { interlayer }\end{array}$ & E. coli strain & Bacteria growth & $\begin{array}{l}1 \% \text { w/v NDs: } 95 \% \text { inhibition growth (no NDs: } 30 \% \text { ). } \\
\text { Involvement of NDs in cell walls damage, thus, in cell } \\
\text { death. Prolonged antibacterial activity }\end{array}$ & 62 \\
\hline
\end{tabular}




\begin{tabular}{|c|c|c|c|c|c|c|}
\hline $\begin{array}{l}\text { ND type/purification } \\
\text { method/impurities } \\
\text { content/coating }\end{array}$ & Global system & $\begin{array}{l}\text { Average size } \\
\text { (technique)/ } \\
\text { others }\end{array}$ & Biological model & $\begin{array}{l}\text { Parameter } \\
\text { assessed }\end{array}$ & Conclusions & References \\
\hline $\begin{array}{l}<10 \mathrm{~nm} \text { DNDs } \\
\text { (surface COOH and } \\
\text { OH), imp.: n.a., used } \\
\text { as-received }\end{array}$ & $\begin{array}{l}\text { NDs-loaded PCL } \\
\text { fibers scaffolds }\end{array}$ & $\begin{array}{l}350-500 \pm 80 \mathrm{~nm} \\
\text { (SEM), fiber size }\end{array}$ & $\begin{array}{l}\text { Chinese hamster } \\
\text { ovarian cells } \\
\text { S. aureus strain }\end{array}$ & $\begin{array}{l}\text { Biocompatibility, } \\
\text { wound } \\
\text { management } \\
\text { Bacteria growth }\end{array}$ & $\begin{array}{l}\text { 1-5\% w/w ND: biocompatibility increase } \\
\text { (hydrophilicity and thermal stability), better } \\
\text { proliferation of epithelial cells and moisture control } \\
5 \% \text { w/w ND: lower bacteria sticking for greater } \\
\text { inhibition growth vs. PCL alone }\end{array}$ & 63 \\
\hline $\begin{array}{l}\text { NDs (surface } \mathrm{COOH} \\
\text { and } \mathrm{OH} \text { ), imp.: n.a., } \\
\text { used as-received }\end{array}$ & $\begin{array}{l}\text { Electrospun NDs- } \\
\text { loaded FG } \\
\text { scaffolds }\end{array}$ & n.a. & hASCs & $\begin{array}{l}\text { Biocompatibility, } \\
\text { tissue engineering }\end{array}$ & $\begin{array}{l}0,0.5 \text { and } 1 \% \mathrm{w} / \mathrm{v} \text { NDs: growing biocompatibility and } \\
\text { metabolic activity in NDs-loaded FG scaffolds, better } \\
\text { proliferation and adhesion of hASCs }\end{array}$ & 64 \\
\hline $\begin{array}{l}25 \mathrm{~nm} \text { HOOC-DNDs, } \\
\text { liquid and air oxid., } \\
\text { imp.: } 0.6 \mathrm{wt} \%\end{array}$ & $\begin{array}{l}\mathrm{ND} @ \mathrm{SiO}_{2} @ \mathrm{DEX} \\
\text { nanogel }\end{array}$ & 390 nm (DLS) & $\begin{array}{l}\text { pH } 7.3 \text { buffer } \\
\text { solution }\end{array}$ & Drug delivery & $\begin{array}{l}30 w t \% \text { DEX maximum loading }(<1 \text { wt\% for ND@DEX), } \\
\text { totally desorbed, in a prolonged manner }(26 \mathrm{~h})\end{array}$ & 65 \\
\hline $\begin{array}{l}5 \mathrm{~nm} \text { HOOC-DNDs, air } \\
\text { and liquid oxid., imp.: } \\
\text { n.a. }\end{array}$ & ND-ODA/DEX & $\begin{array}{l}5.1 \pm 2.2 \mathrm{~nm} \\
\text { (TEM), } \\
\text { deaggregated ND- } \\
\text { ODA, no DEX }\end{array}$ & Arthritic mice limbs & $\begin{array}{l}\text { Immune system } \\
\text { response, bone } \\
\text { volume }\end{array}$ & $\begin{array}{l}16 \mu \mathrm{g} \cdot \mathrm{mL}^{-1} / 0.1 \mu \mathrm{g} \cdot \mathrm{mL}^{-1} \mathrm{ND}-\mathrm{ODA} / \mathrm{DEX}(5 \mu \mathrm{L} \text { injections): } \\
\text { reduction of macrophage invasion and tuning of } \\
\text { inflammatory response. Lower bone degradation ex } \\
\text { vivo. Dose-dependent immunomodulatory effects }\end{array}$ & 66 \\
\hline $\begin{array}{l}\text { 4-5 nm HOOC-DNDs, } \\
\text { liquid oxid., imp.: }<2 \\
\text { wt\% }\end{array}$ & $\begin{array}{l}\mathrm{ND}-\mathrm{NH}_{2}- \\
\text { terminated, } \\
\mathrm{ND}-\mathrm{COOH}\end{array}$ & n.a. & Human PBMCs & $\begin{array}{l}\text { Interactions with } \\
\text { immune cells, } \\
\text { dispersibility }\end{array}$ & $\begin{array}{l}\text { Good uptake in PBMCs. Very aggregated ND-COOH } \\
\text { caused pro-inflammatory responses. ND- } \mathrm{NH}_{2} \text { were } \\
\text { more dispersed and more immunocompatible }\end{array}$ & 67 \\
\hline
\end{tabular}

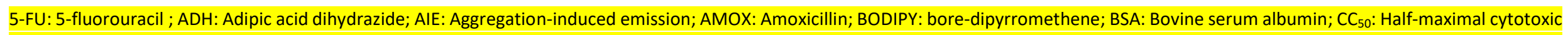
concentration; CD: Carbon dot; Ce6: Chlorine e6; CPT: Camptothecin; CUR: Curcumin; DEX: Dexamethasone; DLC: Diamond-like carbon; DND : Detonation nanodiamond; DOX: Doxorubicin; FG: Fish

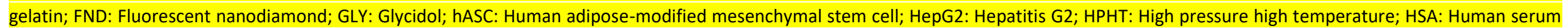
albumin; IC 50 : Half-maximal inhibitory concentration; ICG: Indocyanine green; imp.: Impurities; n.a.: Not indicated; MRI: Magnetic resonance imaging; ND: Nanodiamond; NP: Nanoparticle; ODA: Octadecylamine; PA: Polyarginine; PBMC: Peripheral blood mononuclear cell; PBS: Phosphate buffer saline; PCL: Poly- $\varepsilon$-caprolactone; PCM: Phase-change material; PDA: Polydopamine; PDT:

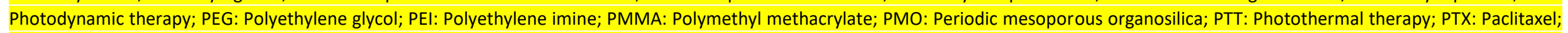
QD: Quantum dot; RE: Rare-earth; SP: Supraparticle; T-EDTA: Trypsin-ethylenediaminetetraacetic acid; TTA: 2-thenoyltrifluoroacetone; UA: Usnic acid; ZnPc: Zinc-based phthalocyanine-derivative. 

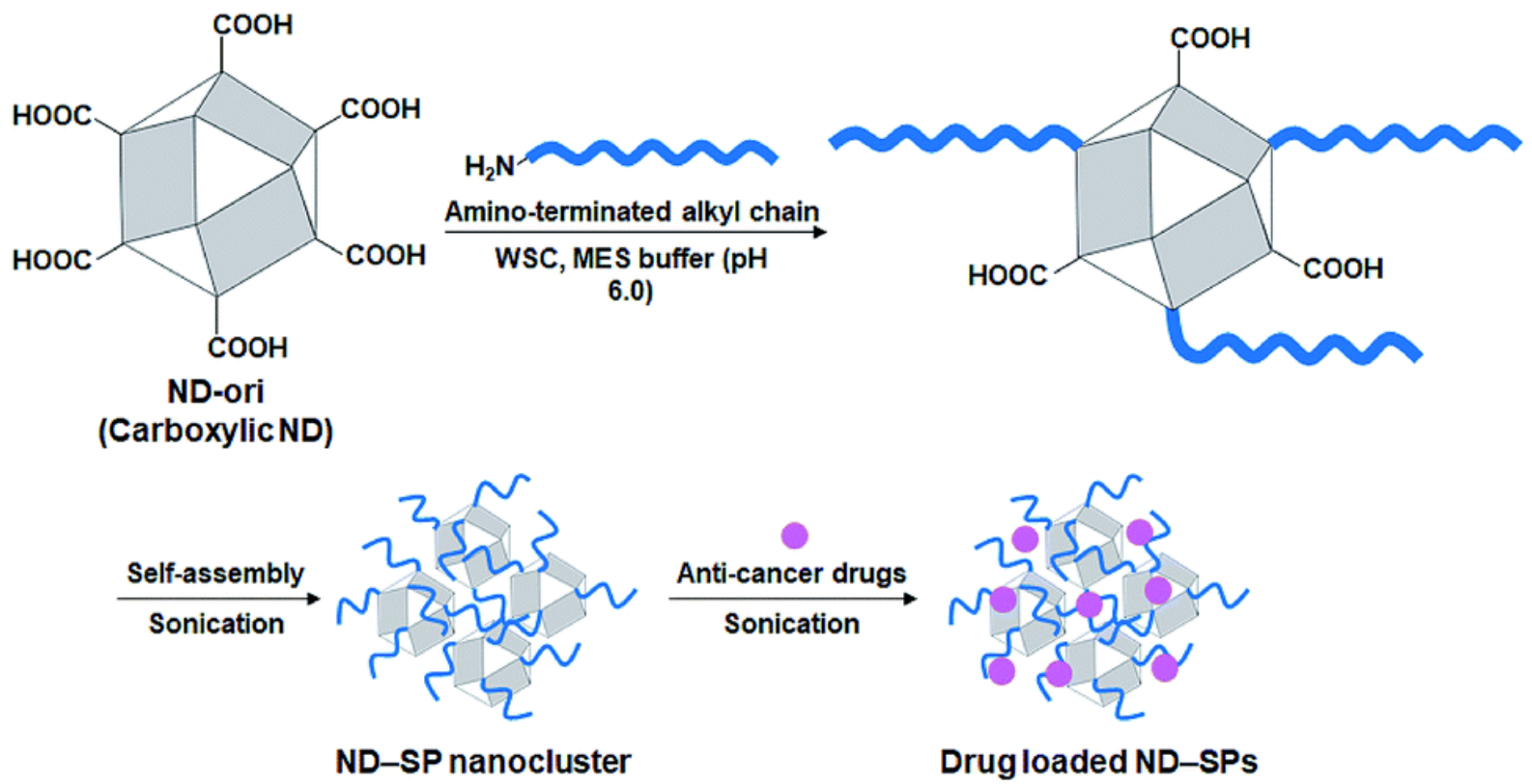

Fig. 1. Synthesis steps of nanodiamond supraparticles loaded with camptothecin from carboxylated detonation NDs. Reproduced from ref. 41 with permission from the Royal Society of Chemistry.

(PEG)-micelles and CPT-intralipid emulsions. The cell viability fell to $10 \%$ on bone osteosarcoma cells (20 $\mu \mathrm{g} \cdot \mathrm{mL}^{-1}$ of CPT), while it reached around $50-60 \%$ for classic CPT-complexes (at same concentration). Moreover, after implementing HT-29 colorectal adenocarcinoma xenografts in mice, ND-CPT synergy significantly reduced tumor volumes compared to phosphate buffer saline (PBS) control measurements. ${ }^{41}$

Another recurrent issue with pristine or modified nanodiamonds is their spontaneous aggregation and limited dispersion in water. Consequently, the design of composites can render NDs more hydrophilic and provide better compatibility with aqueous media. Recently, ND-polymer drug delivery systems showed good dispersibility, biocompatibility and successful transport of doxorubicin (DOX) in hepatitis G2 (HepG2) liver cancer cells. For this purpose, Long et al. functionalized small detonated NDs. Using thiol-ene click reaction with dicumyl peroxide, methyl 3-sulfanyl propanoate radicals were generated. After thiol conjugation onto NDs surface, reaction with hydrazine hydrate led to stable amide functions. In parallel, carbonylated PEG was produced by reaction with 4-carboxybenzaldehyde. Then, PEG and DOX were concomitantly anchored to NDs by hydrazone linkages. In vitro assays evidenced a good cellular uptake of the cargos and a pH-dependent DOX release with good results at $\mathrm{pH}$ 5.4. MTT assays highlighted the therapeutic efficacy of this strategy, demonstrating a good reduction of viability at high concentrations. At $200 \mu \mathrm{g} \cdot \mathrm{mL}^{-1}$ in free drug, the killing effect was about $75 \%$, similar to the result with DOX loading. ${ }^{42}$ This way, dose and relative side effects could be reduced.

Wei's team built a DOX delivery system sensitive to $\mathrm{pH}$-triggered release. At first, a modified polyethylene glycol $\left(\mathrm{H}_{2} \mathrm{~N}-\mathrm{PEG}-\mathrm{COOH}\right)$ was grafted onto carboxylated nanodiamonds, creating an amide group. Subsequently, a glycidol (GLY)-DOX moiety was attached to the terminal carboxyl function of ND-PEG by ester junction with GLY alcohol, reaching a drug loading of $15 \mathrm{wt} \%$. The material structure was well-suited to prevent drug leakage. Tests in PBS containing 10\% FBS revealed no apparent drug release after $50 \mathrm{~h} .{ }^{44}$ Therefore, when subjected to acidic lysosomes in cancer cells, controllable and extended release of GLY-DOX was detectable by fluorescence intensity measurements, surely arising from ester cleavage. This off-on system was also applied in vitro on HepG2, HeLa and MCF-7 cancer cell lines. High survival rates obtained by MTT assays showed satisfactory biocompatibility of ND and ND-PEG nanoparticles. In contrast, when DOX was liberated from ND-PEG-GLY-DOX, cell viability was 
very low, indicating good tumor proliferation inhibition. Besides, the platform could affect other processes such as migration, apoptosis and cell cycle. Noteworthy, mice body weights were relatively stable, while a serious weight loss occurred with only GLY-DOX. In conclusion, this rich study provided an efficient design for actuable drug transport and drug liberation, and associated monitoring. ${ }^{44}$



NDs

$\mathrm{ND}-\mathrm{COOH}$

ND-APTES<smiles>O=C(CC(=O)C(F)(F)F)c1cccs1</smiles>

TTA

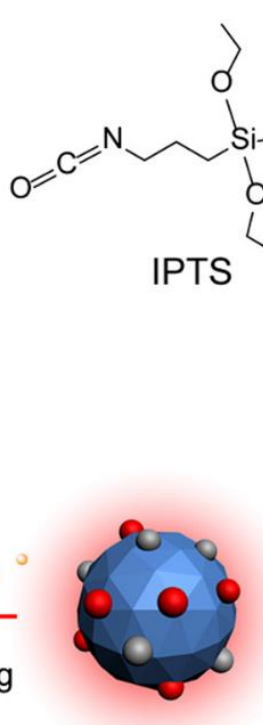

Drug loading

$\mathrm{ND}-\mathrm{COCl}$


ND-TTA:RE-Dox

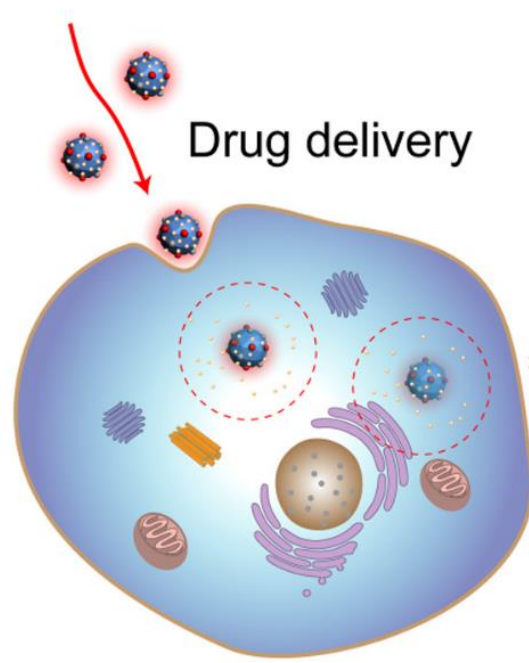

ND-TTA:RE
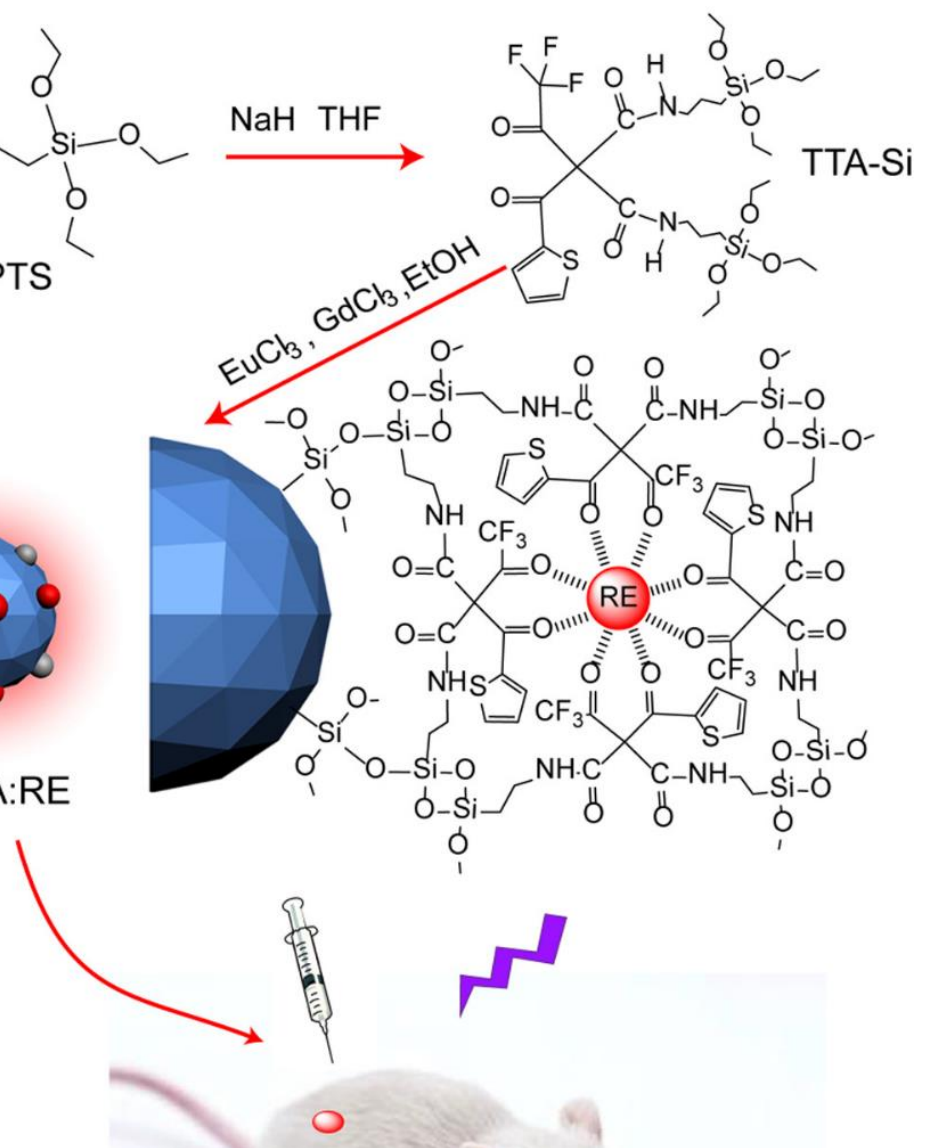

Bio-labelling

Fig. 2. Schematic view of ND functionalization with thionyl chloride and alkoxysilanes, ultimately for rare-earth immobilization and drug loading for theranostic application. Reprinted from ref. 46, Copyright 2018, with permission from Elsevier.

Some research about selectivity competence for pancreatic ductal adenocarcinoma was conducted recently. ${ }^{45} \mathrm{NDs}$ with different surface terminations were loaded with DOX and tested against this rare cancer. Among ND-NH $2, \mathrm{ND}-\mathrm{COOH}$ and ND-PEG, the latter conferred the best catch and release ability toward DOX. Up to $75 \%$ of drug was complexed by adsorption on NDs surface for an initial weight ratio 
of 5:1 ND-PEG:DOX. In different media, the release efficiency was inversely proportional to the $\mathrm{pH}$ value, and best ratios were obtained in acidic environment $(\approx 95 \%$ at $\mathrm{pH} 2)$. In vivo imaging systems with fluorescence snapshots on NSG mice, as well as ex vivo biodistribution analyses revealed a remarkable accumulation of DOX in the tumors, $48 \mathrm{~h}$ post-injection, indicating a good cellular uptake. This led to lower tumor sizes - after treating the animals for 3 weeks - compared to the free drug. Interesting cytotoxicity of ND-PEG-DOX incorporated in BxPC3 PDAC cancer cells (3D spheroids) was also visible, while ND-PEG without loaded drug were non-toxic. After $96 \mathrm{~h}$ exposure, almost all cells were eradicated. ${ }^{45}$ Altogether, these systems seem to be efficient for drug delivery purposes, as they promote good biocompatibility and extended drug release.

Nanodiamond fluorescence wavelength is sometimes too short for drug labeling and cell tracking. Qin et al. fabricated an innovative material for both therapy and diagnosis purposes using RE-based complexes with nanodiamonds to enhance optical properties. Several steps were necessary to build these materials. In a first part, NDs surfaces were purified by thermal annealing, carboxylated and then partially acylated using $\mathrm{SOCl}_{2}$. To follow, 2-thenoyltrifluoroacetone (TTA) and NDs were silylated with 3-isocyanatopropyltriethoxysilane and 3-aminopropyltriethoxysilane, respectively. Finally, ND-Si and TTA-Si were mixed in presence of europium and gadolinium RE to obtain highly stable biolabelling and drug delivery systems (Fig.2). These ND-based particles were loaded with up to $37.5 \mathrm{wt} \%$ in DOX for an initial feeding of $60 \mathrm{wt} \% .{ }^{46}$ Drug adsorption was typically between $\mathrm{DOX} \mathrm{NH}_{3}{ }^{+}$groups and $-\mathrm{CO}$ containing groups from NDs surface. When incorporated in 96-well plates containing gastric cancer cells, they showed anticancer activity equivalent to unentrapped DOX, but with significant prolonged release certainly originating from ND-Si moiety stability.
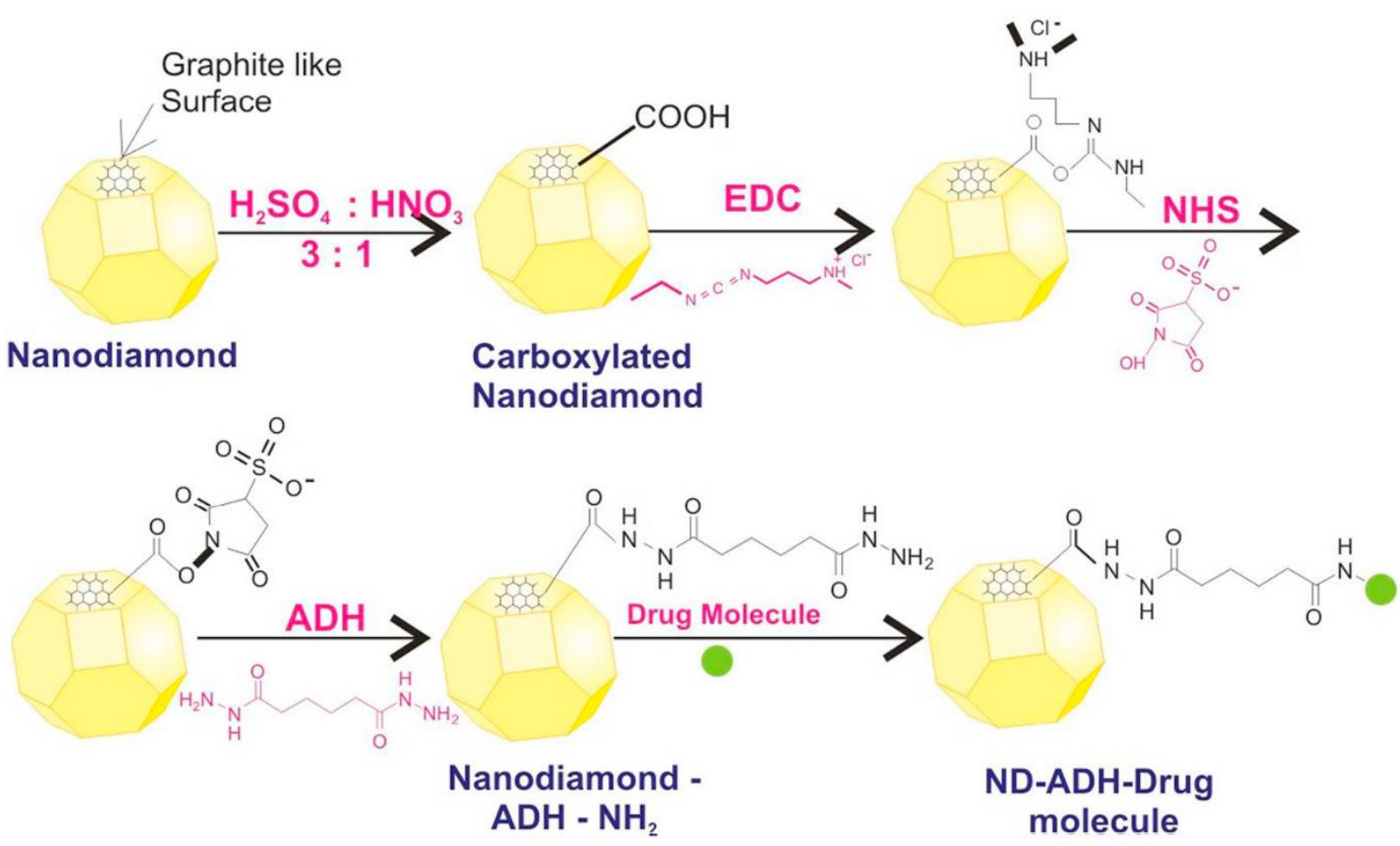

Fig. 3. Synthesis of ND-drug conjugate by activation of surface carboxyls groups for carbodiimide conjugation using adipic acid dihydrazide. One anticancer drug among curcumin, usnic acid and 5-fluorouracil was then loaded. Adapted from ref. 47, Copyright 2019, with permission from Elsevier.

Garg et al. investigated the combination of ND covalently bound to curcumin, usnic acid or 5fluorouracil after several functionalization steps. After an initial purification of bare nanodiamond powder in ND-COOH, NDs surface was modified with 1-ethyl-3-(3-dimethylaminopropyl) carbodiimide 
hydrochloride and $\mathrm{N}$-hydroxysuccinimide to activate carboxyl function reactivity for carbodiimide conjugation with adipic acid dihydrazide (ADH). Lastly, one of the three above-mentioned drugs was conjugated by substitution with the terminal hydrazide, reaching about $90 \%$ loading (Fig.3). Tests in PBS with free drugs indicated their almost total release in $3 \mathrm{~h}$, whereas the conjugates showed prolonged drug liberation for $96 \mathrm{~h}$, due to the hydrophilic properties of nanodiamonds. ${ }^{47}$ With increasing acidic conditions, greater amounts were freed from NDs. Sulforhodamine B trials evaluation of the cytotoxicity on human MCF-7 and HepG2 cancer cell lines revealed a dose-dependent growth inhibition for all ND-drug couples and antitumor drugs. Tumor killing effect was related to drug internalization in nucleus after escaping from intracellular lysosomes, leading to an inhibition of DNA production. These conjugates could be further investigated for applications in targeted cancer treatment as strong therapeutic efficacy was achieved at relatively low concentrations $\left(80 \mu \mathrm{g} \cdot \mathrm{mL}^{-1}\right){ }^{47}$

Tumor therapy can be very limited by interactions occurring between drugs and biomolecules from our blood, such as human serum albumin (HSA), the most profuse protein.

Hekmat et al. recently presented a study where they admixed nanodiamonds, paclitaxel (PTX) chemotherapeutic agent and HSA in tris(hydroxymethyl)aminomethane buffer. Zeta potential, DLS, and several analytical methods highlighted a complexation of PTX + NDs with the above-mentioned protein. For example, steady-state spectroscopy revealed a fluorescence-quenching phenomenon of tryptophan intrinsic fluorophore moiety of HSA. In presence of PTX, NDs or PTX + NDs, fluorescence emission intensity was weakened, and a blue shift occurred. One answer could be that tryptophan surface was clustered by specific interactions with the molecules, inhibiting the fluorescence properties. Hence, HSA-PTX solutions with NDs were prepared to further examine their bioactivity and therapeutic potential. Drug release studies over time indicated a good stability of HSA-PTX + NDs systems in the bloodstream. Indeed, only $35 \%$ of PTX + NDs were released in physiological media after $48 \mathrm{~h}$, while the results in $\mathrm{pH} 4.7$ media were about $85 \%$. These results among others suggested a preferential targeting of tumor sites, with a better affinity for acidic lysosomes in cells, which might be ascribed to enhanced permeability and retention (EPR) effects as albumin specifically bind to Gp60 (glycoprotein of $60 \mathrm{kDa}$ ) and secreted protein acidic and rich in cysteine (SPARC) receptors that are expressed by endothelial cancer cells. ${ }^{48,68}$ Once this mixture was integrated in vitro, an important reduction of MDA-MB-231 human breast cancer cells multiplication was achieved, contrasting with bare NDs and free drug influence. Moreover, at minor NDs and PTX concentrations versus established half-maximal inhibitory concentration $\left(\mathrm{IC}_{50}\right)$ values for these cell lines, the cell viability largely dropped, providing a synergistic effect of the two materials. This could be correlated with HSA higher binding force in buffers containing PTX + NDs than with PTX or NDs alone. ${ }^{48}$ For this reason, it is believed that these systems could furnish good benefit-risk balance in future in vivo inquiries.

\subsection{Photothermal and photodynamic therapies against cancer}

In addition to chemotherapy and radiotherapy, some new techniques presenting limited undesirable effects are emerging to fight cancer. This is the case of photothermal therapy, based on light conversion into heat, and photodynamic therapy, inducing a production of reactive oxygen species. These two phenomena can lead to cells' damaging or even their destruction. By combining a light source (laser, LED, etc.) with a photosensitizing agent, high toxicity levels can be reached. Moreover, for a better treatment efficacy, just like in many therapies, the addition of targeting moieties and the use of biodegradable systems are much exploited. ${ }^{3,69}$

Maziukiewicz et al. examined the synergistic photothermal and photochemical effects of NDs coated with indocyanine green (ICG) fluorophore and biomimetic polydopamine (PDA). The synthesis protocol started with dopamine hydrochloride applied on top of sonicated NDs exhibiting different surface 
functionalities (1:- $\mathrm{COOH} ; 2$ :-alkyl; 3: - $\mathrm{H}$ and $-\mathrm{NH} 2$ ) in a tris(hydroxymethyl)aminomethane buffer. After polymerization process of dopamine in ambient conditions for $24 \mathrm{~h}$, ICG was added in the suspension and the mixture reacted in dark conditions for another $24 \mathrm{~h}$. The authors conjectured a $\pi-\pi$ bonding

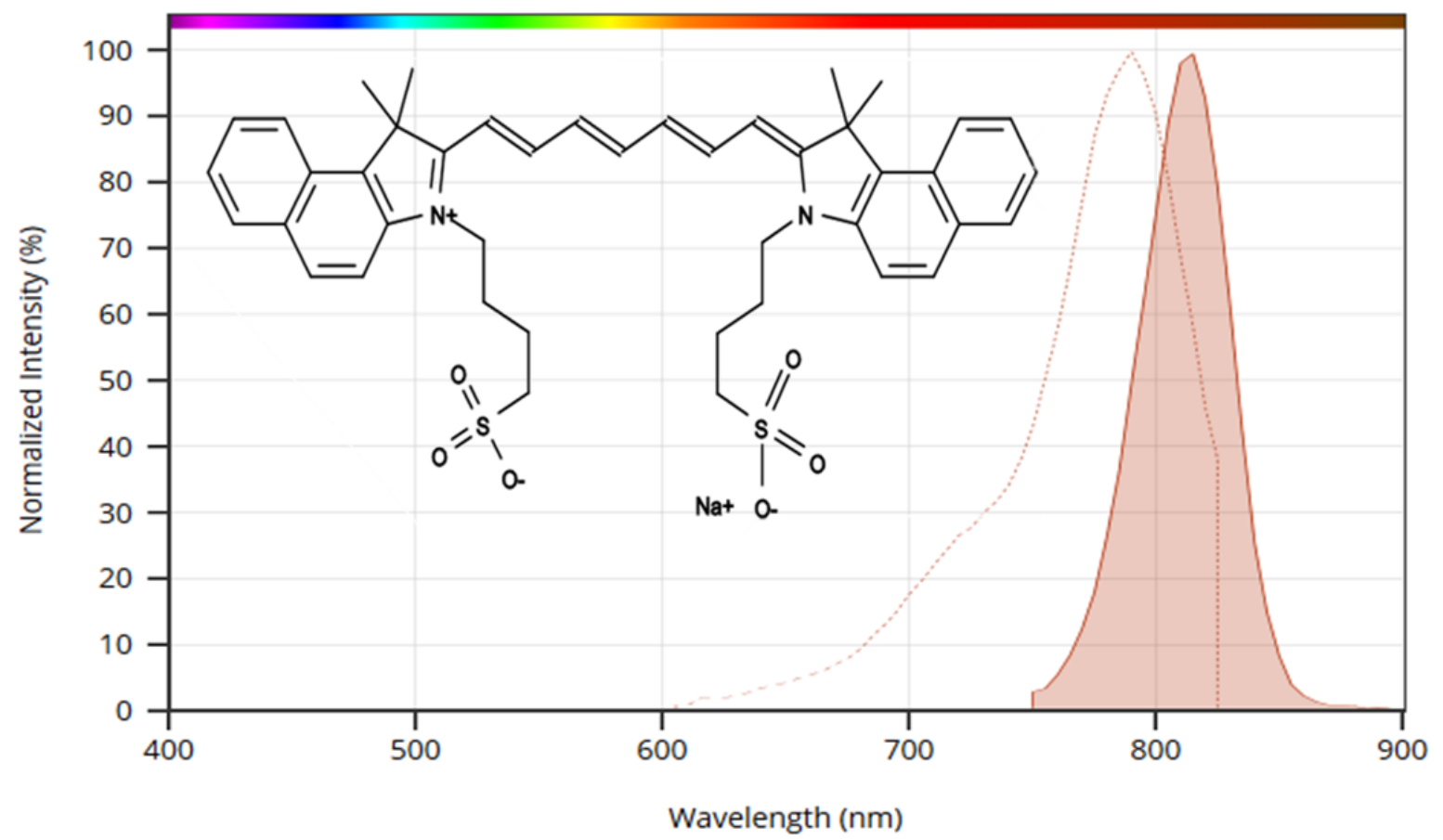

Fig. 4. Chemical structure of indocyanine green (ICG, CAS 3599-32-4) dye. Typical representation of ICG absorbance (dotted lines, maximum close to $800 \mathrm{~nm}$ ) and emission (filled area, maximum close to $810 \mathrm{~nm}$ ) spectra. Copyright @ 2019 AAT Bioquest, Inc.

between aromatic cycles from PDA and ICG. According to their calculations of photothermal conversion ability, this strategy brought a notable increase of temperature with NDs@PDA (36.5\%) and NDs@PDA@ICG (44.5\%) compared to the three ND groups $(<10 \%)$. Referring to its absorption profile, ICG exhibits a maximum absorbance in the NIR region $(\approx 800 \mathrm{~nm}$, Fig.4), indicating good photophysical properties for theranostics and low autofluorescence photobleaching in biological environments upon irradiation. This maximum was also found on the ICG-based core-shells. Hence, WST-1 assays in vitro demonstrated that, after irradiating NDs@PDA@ICG at 808 nm, glioblastoma cell viability completely dropped (10\%), in comparison with dark samples (no laser, 80-90\%), NDs@PDA (45\%) and simple NDs (70\%). ${ }^{49}$ These results unveiled the suitable properties of these systems for PTT, but only above a certain concentration ( 20 or $40 \mu \mathrm{g} \cdot \mathrm{mL}^{-1}$ ), depending on experimental conditions, cell nature and analytical techniques. Notably, core-shell NDs@PDA and NDs@PDA@ICG still had good stability after 5 on-off cycles of irradiation, confirming their good photothermal stability and also ICG high photostability due to strong interactions with PDA. As stated by the authors, their use for repeatable therapy could be an appealing option. ${ }^{49}$ 


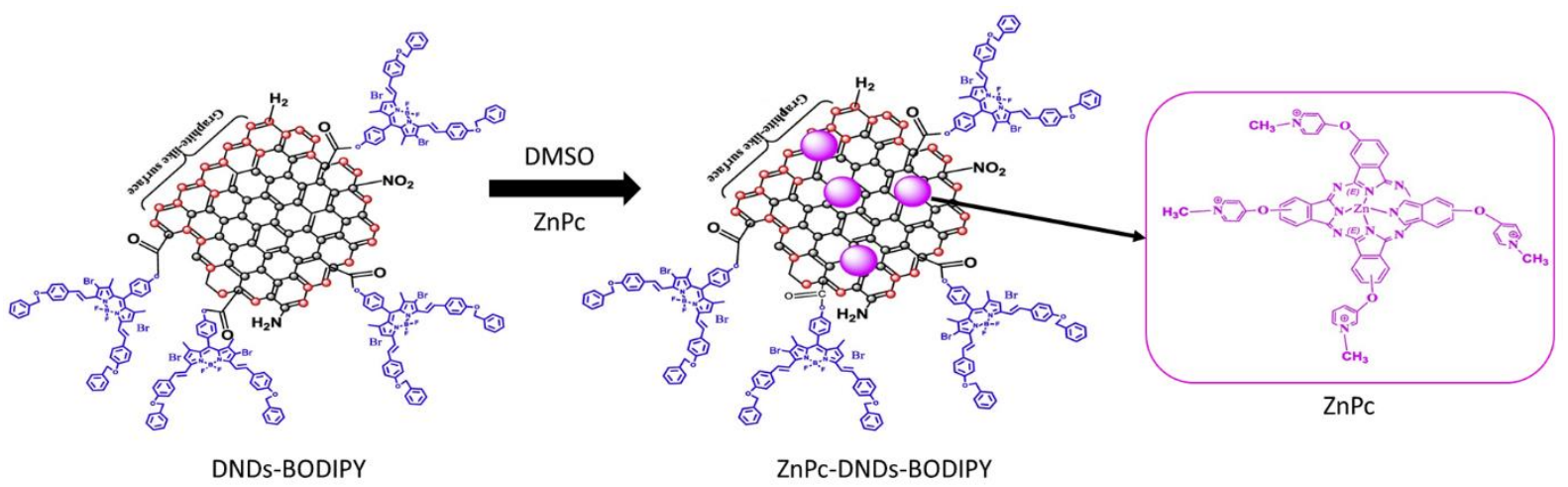

Fig. 5. Conjugation of zinc phthalocyanine derivative to DNDs-BODIPY systems via $\pi-\pi$ stacking. Adapted from ref. 50, Copyright 2019, with permission from Elsevier.

In the experiments of Matshitse's group, three photosensitizers (i.e. DNDs, 3,5-di-p-benzyloxystyryl borondipyrromethene (BODIPY) chromophore and a zinc-based phthalocyanine-derivative (ZnPc) were combined to assess their potential in PDT. The halogenated BODIPY dye was covalently attached to DNDs carboxyl functions via an esterification reaction. 2,9,16,23-tetrakis[4-(N-methylpyridyloxy)]phthalocyanine was basically adsorbed onto NDs surface via $\pi$ stacking due to the presence of $s p^{2}$ graphite-like composition (Fig.5). Triplet and singlet quantum yields assessment (in DMSO or in water with $1 \% \mathrm{v} / \mathrm{v}$ DMSO) showed higher scores when all elements were associated contrary to separated tests. Notably, the singlet quantum values were much higher since singlet oxygen is generated from triplet state, whose quantum yield improved. This could be also attributed to a synergistic effect of the photosensitizers, which provide more enhanced non-radiative transitions than radiative fluorescence. As a result, on MCF-7 breast cancer cells, highest PDT efficiency was obtained by gathering the three constituents, lowering the viability down to $21.4 \pm 5 \%$ with the most concentrated sample at $50 \mu \mathrm{g} \cdot \mathrm{mL}^{-}$ ${ }^{1.50}$ The authors claimed that positive zeta potentials of the structures could facilitate their anchoring and uptake in tumor cells. ${ }^{50}$ Moreover, there was no relative toxicity in dark conditions $(98.6 \pm 3 \%$ viability), reinforcing the biocompatibility of these particles before PDT. Hence, this study highlighted the collaborative effects of photosensitive molecules with DNDs present in the core position due to the great linking potential of their surface.

In another work, Matshitse et al. associated the same metallophthalocyanine with other carbon-based nanomaterials (i.e. CDs and graphene-type QDs), but without BODIPY. As stated in their report, conjugation with NDs induced slightly more singlet oxygen species production than the other materials. In MCF-7 breast cancer cells, there was no dark toxicity of DNDs and ZnPc-NDs. However, excitation of ND-phthalocyanine for PDT evidenced up to $71.2 \%$ killing at $50 \mu \mathrm{g} \cdot \mathrm{mL}^{-1}$, which was close to other carbon-phthalocyanine materials data. ${ }^{51}$

Regarding the photophysical assets, both surface charge and surface composition (specific functional groups and high wt\% graphene-like $\mathrm{sp}^{2}$ ) seem essential to build suitable PDT agents with nanodiamond. 


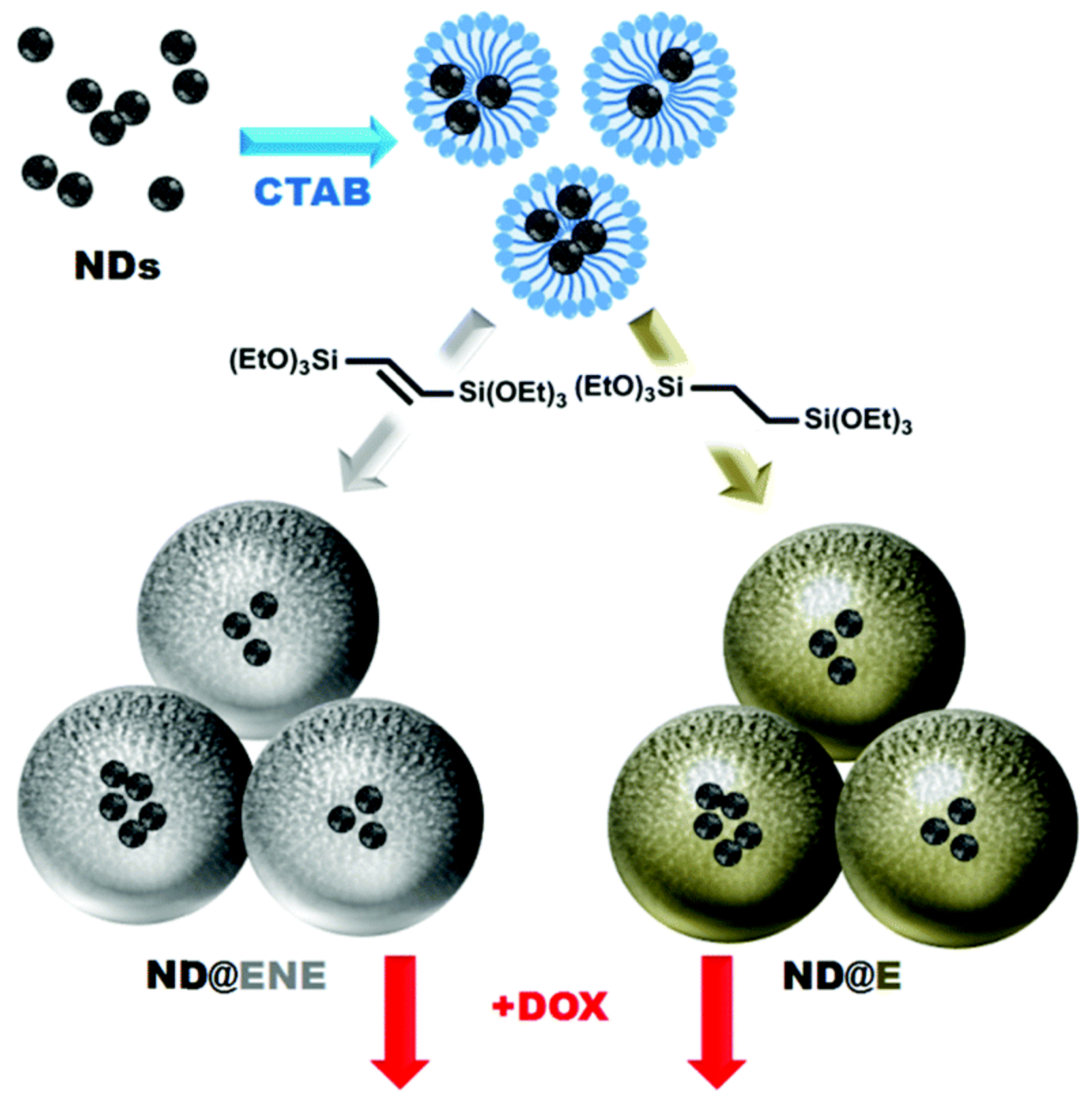

\section{Two-photon Fluorescence \&. Therapy Autonomous Drug Delivery}

Fig. 6. Sol-gel synthesis of ND@ENE and ND@E, respectively from 1,2-bis(triethoxysilyl)ethene and 1,2bis(triethoxysilyl)ethane, for two-photon fluorescence imaging, photodynamic therapy and doxorubicin delivery against MCF-7 breast cancer cells. Reproduced from ref. 52 with permission from the Royal Society of Chemistry.

Our teams recently developed a new strategy for drug delivery purposes. $4 \mathrm{~nm}$ hydroxylated nanodiamonds (NDs-OH) were encapsulated in periodic mesoporous organosilica (PMO) by a simple process. Ethenylene and ethylene-based PMO networks were both prepared, NDs being localized inside PMO nanoparticles. ND@PMO were tested in vitro by two-photon excitation PDT on MCF-7 cell line cultured in DMEM (see global protocol in Fig.6). The photosensitizing capability of ND@PMO was proved by two-photon fluorescence imaging, using a confocal microscope, to evidence good ROS generation and cellular uptake. By irradiating at $800 \mathrm{~nm}$ and incubating for $20 \mathrm{~h}$, at best $39 \%$ killing 
effect was observed. Adding doxorubicin led to enhanced results than bare ND@PMO with notably $57 \%$ cellular eradication. The developed systems were $\mathrm{pH}$-actuable in lysosomal conditions as a fast

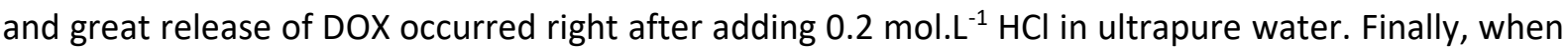
combining drug activity with PDT, up to $87 \%$ cancer cell death was reached at only $5 \mu \mathrm{gg} \cdot \mathrm{mL}^{-1}$ in nanoparticles, promoting a good collaboration of both elements. ${ }^{52}$
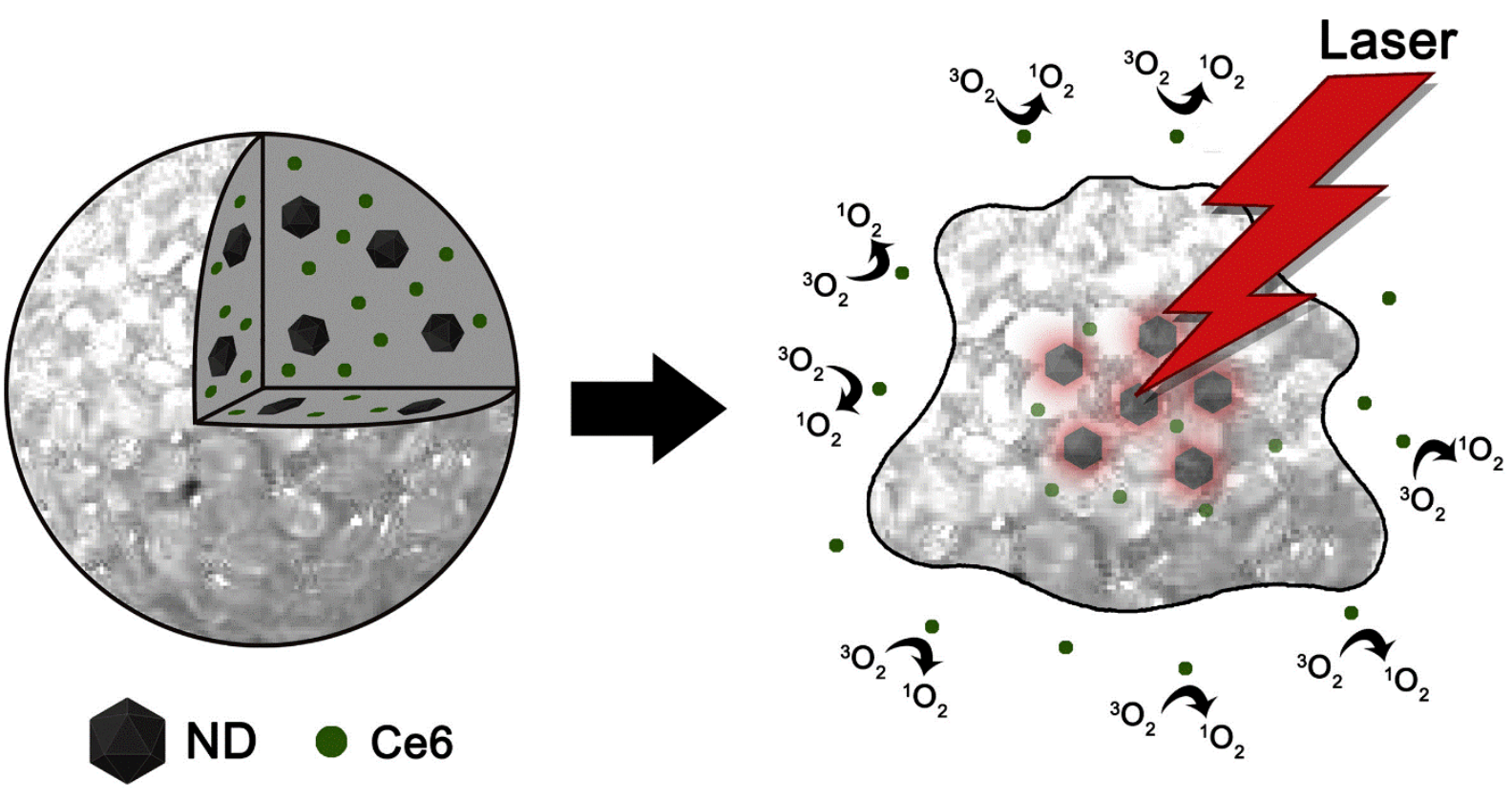

Fig. 7. Lauric acid-based phase change-material spheres incorporated with detonation nanodiamonds (DNDs) and chlorin e6 (Ce6) nanophotosensitizers. Ce6 release was induced by laser irradiation and DNDs local heat generation, respectively participating in singlet oxygen production for photodynamic therapy and tumor cells ablation by photothermal therapy. Reprinted from ref. 53, Copyright 2018, with permission from Elsevier.

Similar to PMO, phase-change material (PCM) nanoparticles have been investigated as a matrix containing DNDs $(<10 \mathrm{~nm}$ ) and chlorin e6 (Ce6) photosensitizer. Organic PCM made of lauric acid $\left(T_{\text {melting }}=43.8^{\circ} \mathrm{C}\right.$ ) reacted with NDs and $\mathrm{Ce} 6$ in a dichloromethane media containing sodium lauryl sulfate surfactant. By laser irradiation, an accurate on-off release of $\mathrm{Ce} 6$ from Ce6/ND/PCM platform was mediated by the thermosensitive properties of DNDs. Even if solutions average temperature was below PCM melting point, Ce6 was released from the matrix as NDs locally generated heat. Besides, ROS generation was enhanced while increasing the time of exposure. A synergistic result of singlet oxygen species and heat production led to interesting therapeutic effect in KB cells, a subline of HeLa cells (Fig.7). The cell death area was enhanced by this PDT and PTT combination. In vivo assays in nude mice displayed continuous tumor size reduction for twelve days, after 4 min irradiations at day 0 and day 6. It was evidenced that $\mathrm{Ce} 6$ and DND particles were still present in sufficient quantities at the tumor site 10 days after intratumoral injection, suggesting a prospective capacity for unique or repeated laser exposure. Noteworthy, no specific conjugation was necessary to build these efficient nanodiamond-based structures that could be good systems for combined PDT and PTT, which harbor many unexplored strategies..$^{53}$

In summary, due to their good optical properties and high loading capacities, nanodiamonds are increasingly implemented in new anticancer drug delivery and combined therapies projects (for instance phototherapy and medication delivery) where they can play a large variety of roles.

\section{Nanodiamonds for bioimaging and labeling}


In the last decades, the vast majority of biological studies using nanodiamonds and applied to bioimaging and labeling operations have been performed using FNDs. Having satisfactory photophysical properties to examine biological samples, and more generally a good contrast level, is obviously important in the election of the best probes, but other features have been identified to improve the feasibility and the quality of the measurements. In this section, recent applications main conclusions will be discussed.

Besides the fabrication of efficient doxorubicin delivery platforms (ND-PEG-GLY-DOX, presented in section 2), Wei et al. created promising drug labels to follow their behavior in cells. Indeed, when entering in acidic intracellular lysosomes, the ester bound connecting ND-PEG and GLY-DOX moieties was cleaved. This induced not only the release of the drug in the tumor cells, but also synchronous fluorescence of GLY-DOX fractions. They were released about one hour after injection according to green fluorescence appearance. After $16 \mathrm{~h}$, fluorescence was still bright, proving that such platforms could be used for long-term cell tracking, contrary to free GLY-DOX. Confocal microscopy imaging allowed confirming GLY-DOX course in time from lysosomes to nucleus, passing by the cytoplasm. ${ }^{44}$ For instance, GLY-DOX fluorescence was overlapped with MCF-7 nuclei stained with Hoechst 33258 blue dye. This study, like many others before, suggests an obvious potential of ND-based materials for theranostics. Here, nanodiamonds were essentially acting as carriers as they displayed protection against degradation, low toxicity and better selectivity toward healthy tissues thanks to EPR effect. ${ }^{44}$

ND@PDA@ICG core-shells presented as photothermal agents in section 2 were a good example of great imaging probes due to their good optical properties. Analyses of polydopamine and photostable indocyanine green, combined with nanodiamonds, revealed multiple assets for high resolution and prolonged fluorescence microscopy to illustrate the efficacy and selectivity of NIR irradiation treatment with the particles towards glioma cancer cells. ${ }^{49}$

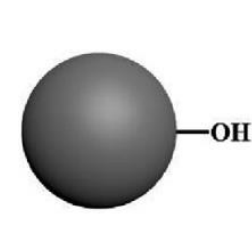

ND

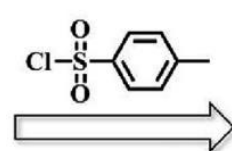

Toluene, TEA
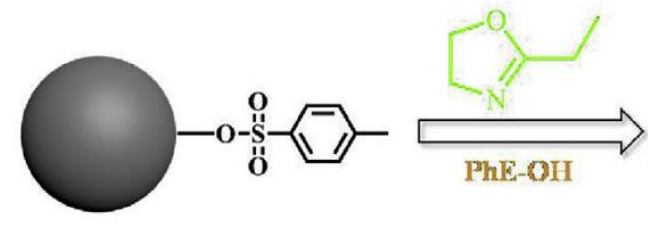

PhE-OH

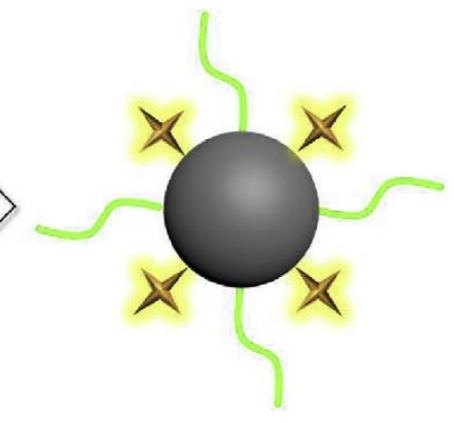

PhE-OH:


ND-PhE-PETOx

Fig. 8. Representation of hydroxylated NDs surface modification with tosyl chloride, acrylonitrile derivative and specific dye (3-(10-hexadecyl-10H-phenothiazin-3-yl)-2-(4-hydroxyphenyl)acrylonitrile: PhE-OH) for bioimaging through fluorescence attributes. Reprinted from ref. 54, Copyright 2020, with permission from Elsevier.

Dong et al. described recently the synthesis and characterization of fluorescent polymer-grafted nanodiamonds. Prepared by a simple synthetic route, the designed composites held great promises for bioapplications, both in drug delivery and imaging. Hydroxylated DNDs were modified with tosyl chloride. Then, 2-ethyl-2-oxazoline ring-opening reaction with tosyl led to chain polymerization. At the same time, 3-(10-hexadecyl-10H-phenothiazin-3-yl)-2-(4-hydroxyphenyl)acrylonitrile specific dye was functionalized onto NDs surface by nucleophilic substitution (Fig.8). This conjugated compound exhibited strong and stable orange fluorescence, following aggregation-induced emission aspect. ${ }^{70}$ As demonstrated by CCK-8 assays in 2929 mouse cells, the particles were non-toxic at higher 
concentrations ( $120 \mu \mathrm{g} \cdot \mathrm{mL}^{-1}, 85 \%$ viability after $48 \mathrm{~h}$ ) than classical cell imaging agents. This great biostability was connected to polymer chains hydrophilicity, which was also responsible for the considerable systems dispersibility in water. In addition, confocal laser scanning microscopy showed good uptake in 1929 cells with a large distribution in the cytoplasm. Thus, these particles could be adapted to serve as theranostic platforms, for instance with an active drug release or in PDT. ${ }^{54}$

Nanodiamonds fluorescence properties are in some cases not enough for selected applications. The innovative material fabricated by Qin et al. for therapy and diagnosis using RE-based complexes had enhanced optical properties. The coordination compounds exhibited an intense and remarkably extended red fluorescence $(613 \mathrm{~nm}$ under UV excitation at $365 \mathrm{~nm}$, best intensity reached after 0.68 $\mathrm{ms}$ ) compared to other well-known biomarkers. Moreover, the in vivo imaging in shaved Kunming mice demonstrated a good fluorescence stability even $4 \mathrm{~h}$ after subcutaneous injection. Additionally, these ND-based complexes held excellent paramagnetic properties from $\mathrm{Gd}^{3+}$, making these complexes potent CAs for T1 weighted MRI. ${ }^{46}$ An optimal combination of dual-modal imaging capacities should be very interesting for further bioapplications studies such as targeted theranostic.

In order to perform skin tissues imaging and sensing, together with active materials for wound healing or skin diseases, nanodiamonds might be of great interest due to their small size and good biocompatibility. In this context, Perevedentseva et al. evaluated the skin penetration capability of different carboxylated NDs in a murine skin model by the combined power of three optical and spectroscopic techniques. To do this, DNDs ( 3 to $10 \mathrm{~nm}$ ) or FNDs (50 or $100 \mathrm{~nm}$ ) were purified and carboxylated in acidic conditions. Then, they were added in neutralized aqueous PBS suspensions at a concentration of $1 \mathrm{mg} \cdot \mathrm{mL}^{-1}$ and incubated for $24 \mathrm{~h}$ in different environments with mice skin pieces. All the applied NDs were able to cross the skin barrier and penetrate the different layers of the epidermis, but the relative penetration mechanisms and the ultimate re-distribution are still requiring further investigations. FNDs of $100 \mathrm{~nm}$ seem to be well-suited specimens for multimodal imaging, notably as contrast agents for optical coherence tomography. ${ }^{55}$ In addition, the good dispersion of NDs within the tissues suggested that they could be applied for transcutaneous delivery with targeting species for selective treatment. Nonetheless, fluorescence lifetime imaging with two-photon excitation at $800 \mathrm{~nm}$ highlighted that the NIR fluorescence of NDs was masked by tissues' autofluorescence, which was brighter and longer. This question will certainly be investigated in next studies.
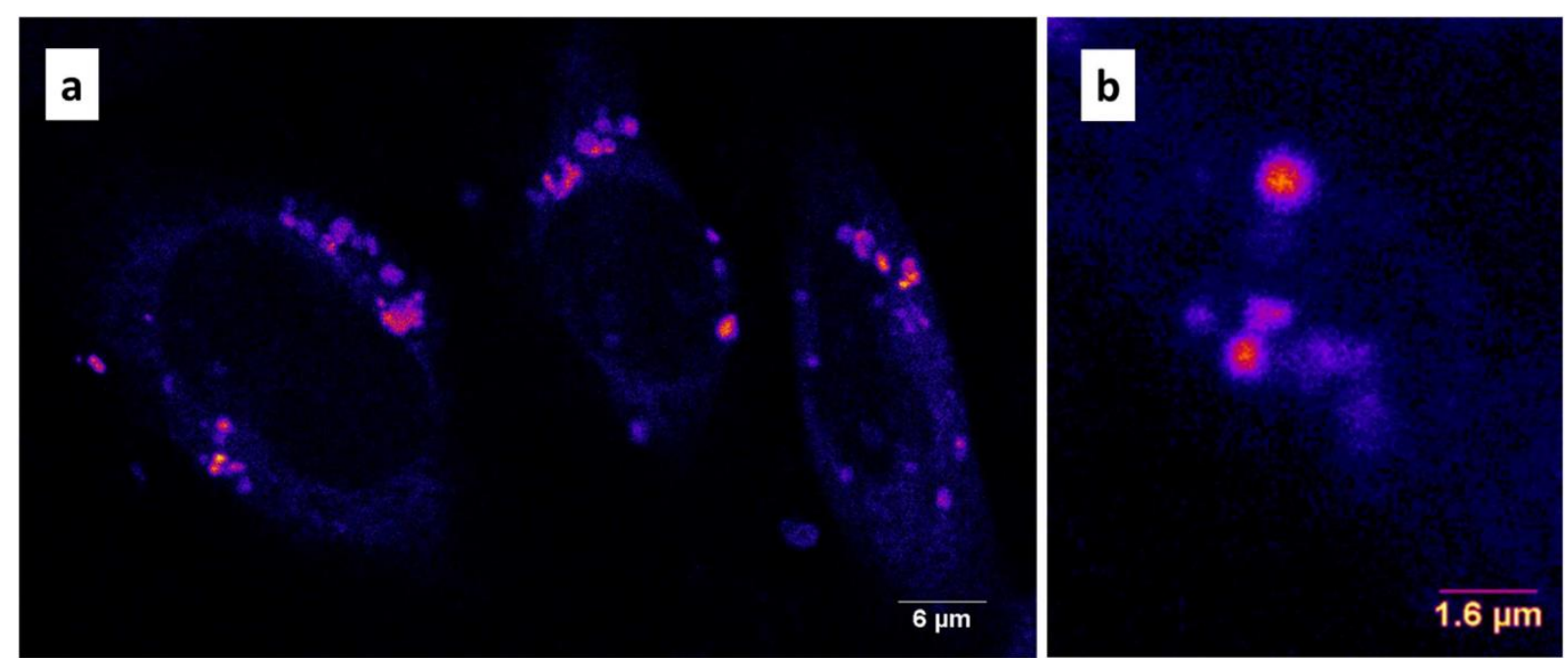

Fig. 9. Visualization of $5 \mathrm{~nm}$ CD-DNDs groups into MDA-MB-231 breast cancer cells excited at $488 \mathrm{~nm}$ by argon laser irradiation. (a) Lower magnification level. (b) Higher magnification level. Original colors modified by the authors. Reproduced with permission from ref. 56, Copyright 2018 IOP Publishing Ltd. 
Nunn's team described innovative and affordable carbon dot (CD) decorated primary DND particles (CD-DNDs). These particles were obtained after several physicochemical treatments of polydisperse NDs, in order to have $5 \mathrm{~nm}$ isolated NPs in the colloids. ${ }^{56}$ They showed comparable photoluminescence intensities to the $20 \mathrm{~nm}$ reference NDs possessing N-V color centers, one key defect responsible for diamond fluorescence. Laser excitation was performed at $532 \mathrm{~nm}$, which is a well-suited wavelength for ND N-V defects, but not much adapted for CD whose optimal excitation range is in UV-blue, underlining the presumption that CD-DNDs held striking potential. In vitro assays with MDA-MB-231 breast cancer cells (Fig.9) confirmed the ability for bioimaging applications as the confocal microscopy images displayed good fluorescence after cellular uptake, with different levels of NPs aggregation. ${ }^{56}$ Moreover, CD-DNDs exhibited good biocompatibility in zebrafish during the development of embryos. Nonetheless, the clustering effect of the particles will surely need the grafting of chemical functions to apply these NPs in the biomedical field. For instance, examining questions of clearance and accumulation in various organs and blood streams would be relevant. These last years, due to its high resolution, electronic microscopy has been much employed in combination with optical imaging to better understand the living. To this extent, CD-DNDs could perfectly match with correlative lightelectron microscopy imaging. ${ }^{18}$

Recent experiments described a few more interesting characteristics of materials composed of nanodiamonds: low toxicity in normal tissues, good protection against degradation, along with sufficient biocompatibility and dispersibility, and high selectivity levels to target molecules and to bypass natural barriers like skin layers. ${ }^{44,49,54,55}$ To answer the current challenges, more attention should be given to the use of NDs in multimodal imaging and emerging technologies by tapping their multiple intrinsic defects and versatile surface properties. ${ }^{56}$ In this respect, chemical modification and purification protocols seem fundamental to design efficient bioactive systems.

\section{Nanodiamonds for fighting antibacterial infections}

(a)
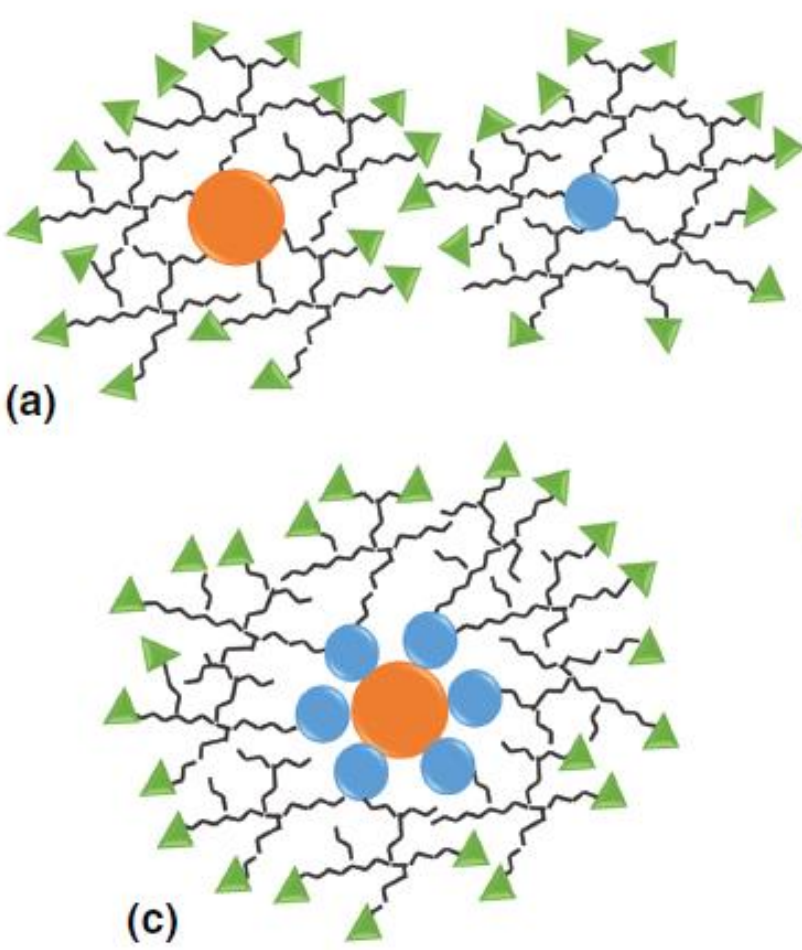

(b)


NDPs

\section{Drug}

Fig. 10. Three different synthesis strategies of magnetite and ND particles with PEI for amoxicillin transport. (a) $\mathrm{Fe}_{3} \mathrm{O}_{4}-\mathrm{PEI}$ and ND-PEI mixture. (b) ND loaded in $\mathrm{Fe}_{3} \mathrm{O}_{4}-\mathrm{PEI}$ particles. (c) PEI loaded in ND-Fe $\mathrm{O}_{4}$ particles. Adapted from ref. 58 with permission from American Scientific Publisher. 
The use of nanodiamonds against antimicrobial infections using classic antibiotic, protein and carbohydrate delivery has already proven its worth even though there is still a lot of progress to make such as developing new strategies considering release specifications.

Rouhani and Singh evaluated the potential of polyethylene imine (PEI)-grafted $\mathrm{Fe}_{3} \mathrm{O}_{4}$ and $\mathrm{ND}$ hybrid platforms. Three different methodologies were elaborated to associate the polymer and the NPs, before amoxicillin (AMOX) loading by covalent bonding with PEI. First, neither AMOX nor NDs attachment was visible by previously mixing ND-PEI and $\mathrm{Fe}_{3} \mathrm{O}_{4}-\mathrm{PEI}$ particles (Fig.10a). Then, another protocol with ND loading on $\mathrm{Fe}_{3} \mathrm{O}_{4}$-PEI prior to PEl loading showed high particle diameters (Fig.10b).

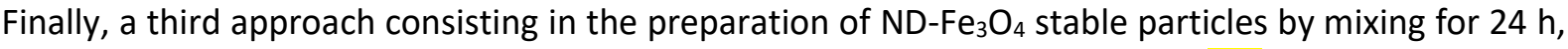
collecting with a magnet, and then, loading NPs with PEl, was adopted (Fig.10c). Their conclusions highlighted the good suitability of the last system as it offered a continuous liberation of AMOX (cumulatively, $77 \%$ at $37^{\circ} \mathrm{C}$ ) in acidic conditions for $180 \mathrm{~h}$. In the contrary, other protocols, including experiments without any ND, showed effective drug delivery for $24 \mathrm{~h}$ only, and more agglomeration occurred, leading to an inconstant release ${ }^{58}$ Interaction of ND particles with hydrophobic molecules seem to be influencing their release from multicomponent platforms.

Just as drug release, cytotoxicity level and biodegradability are important parameters in the light of the cures for bacteria eradication. Chang et al. studied the role of NDs decorating silver nanoparticles (Ag NPs) as the former can be highly biocompatible and the latter is a well-known natural antibiotic. The main target of this study is to design a useful technique to face common issues encountered with high doses of nano-sized $\mathrm{Ag}$ regarding antimicrobial resistance, namely cytotoxicity and aggregation. First, Ag NPs were capped with citrate through chemical reduction using $\mathrm{AgNO}_{3}$, reaching a size of 17 $\pm 6 \mathrm{~nm}$. Then, the Ag NPs were bound to polyarginine (PA)-coated NDs, thanks to the reaction between carboxylate functions of NDs with amine moieties on PA. At the end, BSA serum albumin (BSA) was coated onto the nanoparticles, forming Ag-ND@BSA nanoplatforms of $120 \pm 30 \mathrm{~nm}$, able to interact with classical bacteria $(1-2 \mu \mathrm{m})$. Optical densities and adenosine triphosphate production level tests on E. coli strains confirmed this statement. Compared to the control data, Ag-ND@BSA demonstrated considerable bactericidal activities all along 36 days experiments at $250 \mu \mathrm{g} \cdot \mathrm{mL}^{-1}$, which was far below the estimated half-maximal cytotoxic concentration $\left(\mathrm{CC}_{50}\right)$ value. In addition, ROS levels and cell viability assays were both in agreement with a low toxic response of the nanoparticles on various human cells, even at $500 \mu \mathrm{g} \cdot \mathrm{mL}^{-1}$ and after three days of analyses. ${ }^{59}$ Compared to previous studies with similar efficacy, the main outcomes with ND and BSA were that antibiotic doses were decreased, given the high selectivity for E.coli. 

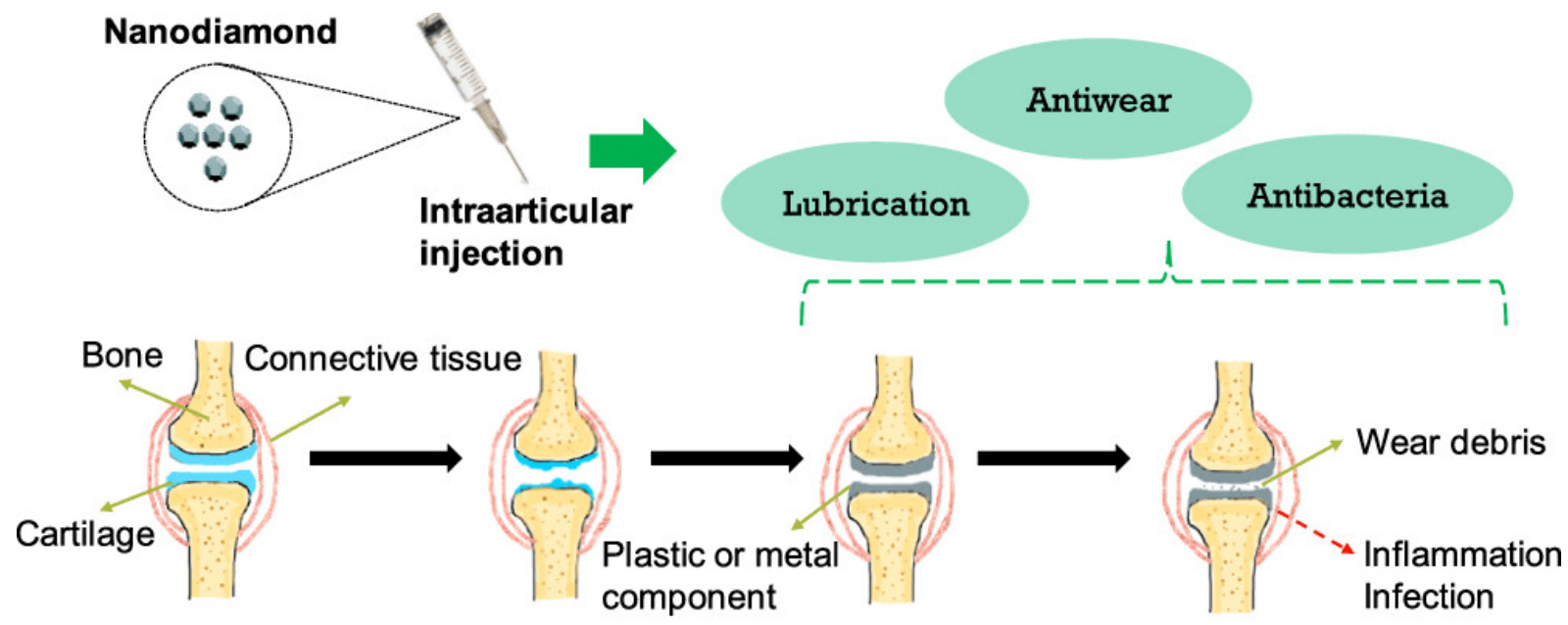

\section{Normal joint Degenerative joint Artificial joint Artificial joint}

Fig. 11. Multifunctional features of nanodiamonds injected in artificial joints. Reprinted with permission from ref. 60. Copyright 2019 American Chemical Society.

Even more interestingly, recent studies described NDs direct action against microbes by different strategies. ${ }^{60,61}$ In artificial joints and implants, poor material mechanical properties and infectious risks are frequent drawbacks. In their work, Shirani et al. assessed the bactericidal and tribological effects of DNDs in titanium (Ti)-polyethylene artificial joints interfaces to reduce inflammation and infection issues (Fig.11). Raman and energy-dispersive spectroscopy analyses of sliding contact areas between Ti ball and polymer surface demonstrated that NDs were mostly present inside the wear track, which corroborated with low friction and wear coefficients. Considering these good mechanical properties of NDs, enlarged lifetime for such implants and better safety for the patients could be reached. Moreover, highly concentrated solutions of NDs in presence of BSA were non-toxic on MC3T3-E1 bone cells, contrasting with 10 to $20 \%$ of viable cells with bare NDs. Following this, the antibacterial effectiveness of BSA-stabilized NDs was almost inexistent while aggregated NDs greatly impacted $S$. aureus growth, by surface carboxyl moiety interaction with bacteria peptidoglycan layer. Unexpectedly, there was no bactericidal effect on E. coli strains. ${ }^{60}$ This result could be related to the cell wall composition ( $E$. coli has a phospholipidic external membrane that $S$. aureus does not have) or could originate from too close surface potential values of diamond and E.coli negatively charged surfaces. Zeta potential of bacteria is an important parameter to consider in cell damaging capabilities and can be tuned by several factors such as high temperature, $\mathrm{pH}$ or surfactants. ${ }^{71,72}$ For future in vivo applications, a compromise between BSA anti-flocculation nature and NDs bacterial disruption ability should be necessary. One can say that NDs low aggregation state is generally characteristic of high viability towards cells. Thus, modifying NDs surface with suitable functional groups and targeting moieties could help to provide superior benefit-risk balance. 




Fig. 12. Antimicrobial capacity of DLC coatings doped or not with $1 \% \mathrm{w} / \mathrm{v}$ NDs and after $6 \mathrm{~h}$ incubation with $\mathrm{E}$. coli strains. The authors results demonstrated significant growth inhibition with DLC-ND systems compared to streptomycin positive control (15 mg. $\mathrm{mL}^{-1}$ ) and ultrapure water negative control. Reprinted from ref. 62, Copyright 2019, with permission from Elsevier.

Comparably, poly (methyl methacrylate) (PMMA), a well-known material for dental applications, does not exhibit ideal mechanical properties. Consequently, doping the systems with various NPs has been tested and brought a successful contribution. In a late study, DNDs were experimented for this purpose by Mangal's team. Different amounts of nanoparticles (from 0.1 to $0.5 \mathrm{wt} \%$ ) were incorporated within methyl methacrylate monomeric solution. Then, adding autogenous PMMA resin in the mixture generated autogenous polymerization. Better efficiency was provided by homogenous distribution of the particles in the matrix, which was possible here by simple stirring and ultrasonication steps during production of the hybrid materials. ND-PMMA mechanical properties were assessed by physical measurements, concluding to enhanced flexural strength and elastic modulus compared to references holding ZrO particles or without doping. To go further, antimicrobial properties of ND-PMMA were assessed on Candida Albicans (renowned fungi for its involvement in many oral infections) and showed better resistance over controls. In addition, ND-based samples demonstrated a significant biofilm growth inhibition on salivary-derived biofilms from human donors without dental problems. ${ }^{61}$ Over and above their good mechanical properties, these patterns could be good fungicide agents. Further investigations about their impact on microbial strains would be interesting.

According to previous studies, diamond-like carbon (DLC) coatings are also competent materials against bacteria in addition to their resistance to corrosion phenomena. In a very recent work, DNDs were carboxylated by oxidation during thermal annealing, and then suspended in hexane to form DLCND suspension. To enhance $\mathrm{Ti}_{6} \mathrm{Al}_{4} \mathrm{~V}$ substrate compatibility with ND-doped DLC, a thin film of silane derivative was applied on the alloy before performing plasma-enhanced chemical vapor deposition. During the evaporation process, methane plasma generating hydrogen species stabilized DLC-ND 
drops covering on $\mathrm{Si}-\mathrm{H}$ interlayer. The final multilayer materials presented interesting corrosion rates, twice lower than $\mathrm{DLC}$ or $\mathrm{Ti}_{6} \mathrm{Al}_{4} \mathrm{~V}$ alone. Alongside anticorrosive properties, antibacterial activity of these materials was tested on $E$. coli strains. The article pointed out the potential role of agglomerated NDs in damaging cell walls, leading to cell apoptosis. With $1 \% \mathrm{w} / \mathrm{v}$ ratio in ND, coatings induced $95 \%$ bacteria growth inhibition after $6 \mathrm{~h}$ (Fig.12), whereas bare DLC films achieved only 30\% inhibition. Nevertheless, after $18 \mathrm{~h}$ incubation, the ND quantity was apparently not enough to block multiplication of remaining bacteria, as $74 \%$ bacteria were still alive in the culture media and extra studies would be needed to know the leeway regarding ND concentrations without being too much toxic for potent bioapplications. ${ }^{62}$

To sum up, these latest projects demonstrated the reinforcing role of NDs in the treatment of microbial infections, including serious features, especially as an active moiety against pathogen proliferation and biofilm growth.

\section{Tissue repairment strategies using nanodiamonds' features}

In one recent study, Houshyar and co-workers presented an innovative strategy to improve wound healing quality. DNDs were dispersed in a DMF solution containing poly- $\varepsilon$-caprolactone. Then, the mixture was electrospun under precise conditions to design controlled nanofibers networks. According to their results, DNDs were significantly located at the surface of the fibers, as surface energy increased with increasing DNDs weight concentration from 0 to $5 \%$. This resulted in better capillarity and optimal moisture handling in the tissues due to the presence of several $\mathrm{OH}$ polar functions from DNDs, originating from carboxyl and hydroxyl groups. In addition to good viability, better cell proliferation was observed on Chinese hamster ovarian cell models, as higher hydrophilicity allowed better interaction. Thus, these ND-based platforms could promote the multiplication of epithelial cells taking part in internal and external surfaces recovery. At the same time, they displayed great anti-adhesive properties against $S$. aureus cells, typically involved in wound infections issues. Confocal microscopy images revealed that nanocomposites with 5\% DNDs significantly inhibited bacterial growth when compared with the polymer alone. ${ }^{63}$ To summarize, tunable surfaces and properties of nanodiamonds particles make them very suitable reinforcements in hybrid materials for tissue repair. 




Fig. 13. Confocal imaging of fish gelatin scaffolds with different NDs weight ratios incubated for different times in hASCs. (a) Live/dead assays of hASCs after 2 days and 7 days. Dead cells are represented in red, while cell proliferation is visible in green. (b) F-actin filaments (green) production by hASCs (nuclei in blue) after $48 \mathrm{~h}$ incubation. Adapted from ref. 64 with permission from MDPI.

Nanodiamonds have recently been combined with biopolymers, stem cells and nanoparticles as potent agents for enhanced tissue reconstruction. Selaru's team fabricated anisotropic fibrous scaffolds of fish gelatin (FG) with a low content of NDs ( $0 \%, 0.5 \%$ and $1 \%)$ and brought them in contact with human adipose-modified mesenchymal stem cells (hASCs) cultures. Gelatin could be a good substrate for cell growth in tissue engineering applications due to its viscoelasticity and rich chemical composition besides the structures tunability brought by electrospinning technology. As shown in Fig.13a, in presence of aggregated NDs in FG fibers, viability of hASCs increased over time, as cell death occurrence (small red dots) became relatively rare and living cells number boomed (their multiplication is visible in green). Moreover, hASCs behavior changed in terms of adhesion and growth, with a tendency to form groups where NDs were located. In Fig.13b, hASCs stacks (nuclei represented in blue on the picture) produced more and more F-actin filaments (in green) after $48 \mathrm{~h}$ of incubation with scaffolds displaying extended amounts of NDs. These results suggested a much better interaction between fibers and stem cells with $1 \%$ of NDs, thus confirming the good biocompatibility of the nanocomposites and enhanced metabolic activity of hASCs. These systems showed very promising 
outcome and could be further developed in the treatment of harmed tissues or for neuroregeneration. ${ }^{64}$

\section{Other challenges around nanodiamonds relevancy}

Nanodiamonds interactions with biological environments and their global behavior are still unclear. Their biocompatibility and their relevancy in some specific therapies have been questioned in recent reports. One tremendous example was about the treatment of glaucoma, where lysozyme-activated desorption of timolol maleate drug encapsulated in ND-based nanogels furnished promising results when deposited into therapeutic contact lenses, demonstrating controlled and prolonged release competency. ${ }^{15,73}$ In these systems, NDs acted as mechanical performance enhancer and promoted efficient drug delivery.

Lately, ND-based carriers of dexamethasone (DEX) also showed active release, this time as a potent solution to treat shocks due to DEX great immunomodulatory and anti-inflammatory properties. Unfortunately, this well-known glucocorticoid presents the inconveniency to display low selectivity during its delivery. To answer this, two strategies using $25 \mathrm{~nm}$ DNDs were compared: ND@DEX and ND@SiO $@ D E X$ core-shells with a mesoporous silica interlayer. In the second method, carboxylated NDs were coated by a sol-gel process using tetraethyl orthosilicate. Then, for both protocols, a DEX solution was added to ND or ND@SiO 2 particles in cyclohexane to form the final core-shells. The ones with silica allowed at best $30 \mathrm{wt} \%$ loading with a sustainable drug release, while the former transported only a short content $(<1 \mathrm{wt} \%)$ that was almost totally released in one hour in various buffer solutions. ${ }^{65}$ According to the authors, the ND@SiO ${ }_{2} @ D E X$ features could be handy to enhance anaphylactic shocks' treatment, but also in other cures in which DEX is already commercialized.



Fig. 14. Sulfonitric acid treatment of 4-5 nm pristine nanodiamond particles to obtain purified NDs-COOH, followed by carboxylate activation using 2-(1H-benzotriazole-1-yl)-1,1,3,3-tetramethylaminium tetrafluoroborate (TBTU), N,N-diisopropylethylamine (DIPEA) and amide formation using N-Boc-aminodiethoxyethylamine to obtain $\mathrm{NDs}-\mathrm{NH}_{2}$. Functional groups quantity and structure proportions were arbitrary drawn. Adapted from ref. 67, Copyright 2020, with permission from Elsevier.

In another study conducted on dexamethasone medicinal effects, materials containing aggregated diamonds were experimented in the context of rheumatoid arthritis. In more details, octadecylamine (ODA)-grafted NDs were synthesized by chlorination of the carboxylated surface of $5 \mathrm{~nm}$ NDs prior to reaction with ODA, and the biggest aggregates were removed by washing and centrifugation processes. Then, dexamethasone was adsorbed onto the particles by a simple condensation reaction protocol overnight. These anti-inflammatory and pro-regenerative probes were studied in human macrophages samples and were incorporated in arthritic mice limbs to get some information about the immunorestrictive power of the materials against collagen type Il-induced arthritis. In contrast with control representative, $5 \mu \mathrm{L}$ injections of solutions containing ND-ODA (15 $\left.\mu \mathrm{g} \cdot \mathrm{mL}^{-1}\right)$, DEX (0.1 
$\mu \mathrm{g} \cdot \mathrm{mL}^{-1}$ ) or ND-ODA/DEX (respectively $16 \mu \mathrm{g} \cdot \mathrm{mL}^{-1}$ and $0.1 \mu \mathrm{g} \cdot \mathrm{mL}^{-1}$ ) lowered the expression of proinflammatory mediators and partially inhibited macrophages invasion in the joints. Therefore, ex vivo microcomputed tomography images showed reduced bone degradation with these solutions, but the authors highlighted opposite effects when working at higher ND-ODA concentration ( $\left.50 \mu \mathrm{g} \cdot \mathrm{mL}^{-1}\right)$, meaning that immune cells modulation and, thus, therapeutic efficacy, are dose-dependent. Further in vivo inquiries will probably give more information concerning the pro-regenerative aptitude of these ND-based structures. ${ }^{66}$

In Fusco's group recent report, human peripheral blood mononuclear cells (PBMCs) were chosen as a model to study biomedical scenarios of NDs interaction with the human body. The aim was to assess immune responses toward functionalized NDs by strongly copying an in vivo behavior. Carboxylated (NDs- $\mathrm{COOH}$ ) and amino-functionalized diamonds (NDs- $\mathrm{NH}_{2}$ ), prepared as shown in Fig.14, were compared. Confocal microscopy images revealed their efficient internalization in PBMCs cytoplasm probably due to their glycolic chain targeting capacity. As stated by multiple gene expression and protein analyses, carboxylated NDs induced significant undesirable pro-inflammatory responses. On the contrary, the authors described that amino-terminated NDs were more immunocompatible, which could be related to their better dispersion state. ${ }^{67}$ Thereby, grafting antibodies or other targeting molecules onto amino-NDs to further study the behavior of the immune system would be worthwhile to extend the knowledge about many diseases and improve their treatment and diagnosis. ${ }^{67}$

To resume, nanodiamonds are presented as promising agents for tissue regeneration and several diseases when combined with other entities (biopolymers, drugs, nanoparticles) in different arrangements (fibrous scaffolds or multifunctional core-shell). By tuning the metabolism of specific biomolecules and by further exploring immunomodulatory processes, enhanced therapies might be reachable. In parallel, care must be taken in designing materials that do not adversely affect the immune system and the body integrity.

\section{Conclusion}

Nanodiamonds already exhibited significant action in tens of bioapplications. The latest approaches and associated results summarized in our review indicated the large application scope of these tiny little gems. As highlighted in the most recent works, rightfully tailored NDs display enhanced biocompatibility and their functionalization with targeting molecules and different moieties led to better selectivity to specific body cells, with generally lower toxicity in healthy tissues, better cellular uptake and sustainable release. Thus, their use as drug carriers for better therapeutic balance is no longer to prove. Nonetheless, the use of aggregated NDs as active therapeutic agents will require more studies to figure out biodistribution and elimination concerns.

The great optical properties of NDs make them suitable for bioimaging, sensing, labeling and phototherapies. For this reason, the scientific community experimented them in a large range of disease treatments and analytical technologies, leading to some input from their use. Moreover, the outlined papers demonstrated that fluorescence is not the only noticeable characteristic of NDs for diagnosis and drug delivery tracking. Their intrinsic core defects and external surface properties, as well as their covalent and non-covalent environment are a reservoir of striking potentials for theranostics and multimodal monitoring with their thermal properties for sensing and phototherapy, and their paramagnetic defects for MRI or correlative light-electron microscopy.

Diamond mechanical attributes are also very interesting in artificial joints and implants, providing lubrication and tribological properties. In addition, better antiproliferative effects were evidenced on 
fungi and bacteria proliferation when materials contained NDs. Similar systems could promptly reduce inflammation and infection symptoms in future wound healing and tissue regeneration applications. One main recent advancement is the immunomodulatory competency of NDs in the cure of a few diseases and stimulated tissue engineering with human mesenchymal stem cells. Puzzling out the biomechanisms behind those themes will certainly expand the knowledge associated to immune system behavior, and NDs could play a leading role for this purpose.

Consequently, the clinical translation of ND particles is currently a serious challenge for the scientific community as many parameters should be validated: appropriate dispersibility to bypass the biological barriers, right size and concentration for safe elimination and a better knowledge about global pharmacokinetics. ${ }^{74,75}$ To elucidate this, reproducible and rigorous procedures should be performed to rightly identify the best ND-based systems able to outpace the clinical standards in terms of safety and efficacy. $3,76,77$ In addition, this translation will require costless manufacturing as most ND synthesis pathways are expensive. Empowering this research field could be worthy, viewing the current elaborated studies and the first clinic validation of a ND-based biomaterial. ${ }^{78}$

From all this information and because nanodiamond-based solutions are more and more studied and commercialized for bio-relative applications, nanodiamonds, among all nanomaterials, are frequently affiliated to a golden future. ${ }^{16,79,80}$

\section{Conflicts of interest}

There are no conflicts to declare.

\section{References}

1. K. J. van der Laan, M. Hasani, T. T. Zheng and R. Schirhagl, Small, 2018, 14, 1703838.

2. $\quad$ R. Namdar and S. Nafisi, Drug Discovery Today, 2018, 23, 1152-1158.

3. M. S. Ali, A. A. Metwally, R. H. Fahmy and R. Osman, Int. J. Pharm., 2019, 558, 165-176.

4. M. Ozawa, M. Inaguma, M. Takahashi, F. Kataoka, A. Kruger and E. Osawa, Adv. Mater., 2007, 19, 1201-1206.

5. G. Y. Gao, Q. Y. Guo and J. F. Zhi, Small, 2019, 15, 1902238.

6. G. Reina, L. Zhao, A. Bianco and N. Komatsu, Angew. Chem., Int. Ed., 2019, 58, 17918.

7. A. Rehman, S. Houshyar and X. Wang, J. Biomed. Mater. Res., Part A, 2020, 108, 906-922.

8. D. Amans, A. C. Chenus, G. Ledoux, C. Dujardin, C. Reynaud, O. Sublemontier, K. MasenelliVarlot and O. Guillois, Diamond Relat. Mater., 2009, 18, 177-180.

9. J. E. Butler and A. V. Sumant, Chem. Vap. Deposition, 2008, 14, 145-160.

10. F. Gorrini, M. Cazzanelli, N. Bazzanella, R. Edla, M. Gemmi, V. Cappello, J. David, C. Dorigoni, A. Bifone and A. Miotello, Sci. Rep., 2016, 6, 35244.

11. N. Panwar, A. M. Soehartono, K. K. Chan, S. Zeng, G. Xu, J. Qu, P. Coquet, K. T. Yong and X. Chen, Chem. Rev., 2019, 119, 9559-9656.

12. H. Zhu, Y. Wang, A. Hussain, Z. P. Zhang, Y. Y. Shen and S. R. Guo, J. Mater. Chem. B, 2017, 5, 3531-3540.

13. J. S. Xiao, X. P. Duan, Q. Yin, Z. W. Zhang, H. J. Yu and Y. P. Li, Biomaterials, 2013, 34, 96489656.

14. Y. Xiong, X. Tian and H.-w. Ai, Bioconjugate Chem., 2019, 30, 1297-1303.

15. S. Chauhan, N. Jain and U. Nagaich, J. Pharm. Anal., 2020, 10, 1-12.

16. N. Prabhakar and J. M. Rosenholm, Curr. Opin. Colloid Interface Sci., 2019, 39, 220-231.

17. Y.-K. Tzeng, O. Faklaris, B.-M. Chang, Y. Kuo, J.-H. Hsu and H.-C. Chang, Angew. Chem., Int. Ed., 2011, 50, 2262-2265.

18. M. D. Torelli, N. A. Nunn and O. A. Shenderova, Small, 2019, 15, 1902151. 
19. R. Fischer, C. O. Bretschneider, P. London, D. Budker, D. Gershoni and L. Frydman, Phys. Rev. Lett., 2013, 111, 057601.

20. J. P. King, K. H. Jeong, C. C. Vassiliou, C. S. Shin, R. H. Page, C. E. Avalos, H. J. Wang and A. Pines, Nat. Commun., 2015, 6, 8965.

21. S. M. Schrader, J. Vaubourgeix and C. Nathan, Sci. Transl. Med., 2020, 12, eaaz6992.

22. M. Ye, Y. Zhao, Y. Wang, N. Yodsanit, R. Xie and S. Gong, Adv. Funct. Mater., 2020, 30, 2002655.

23. M. Sutradhar, H. J. Raj, P. Trigunait, S. Chhaule, R. Ray, U. Roy, R. Das and A. Ghosh, J. Evol. Med. Dent. Sci., 2020, 9, 2284-2288.

24. W. Cao, X. Wang, Q. Li, X. Peng, L. Wang, P. Li, Z. Ye and X. Xing, Mater. Sci. Eng., C, 2018, 92, 307-316.

25. B. A. F. de Camargo, D. E. S. Silva, A. N. da Silva, D. L. Campos, T. R. M. Ribeiro, M. J. Mieli, M. B. T. Zanatta, P. B. da Silva, F. R. Pavan, C. G. Moreira, F. A. Resende, A. A. Menegario, M. Chorilli, A. V. D. Netto and T. M. Bauab, Mol. Pharmaceutics, 2020, 17, 2287-2298.

26. A. Kumar, S. Gahlyan, R. Thakur, S. Devi and S. Duhan, J. Nanosci. Nanotechnol., 2020, 20, $4210-$ 4215.

27. Y. C. Yeh, T. H. Huang, S. C. Yang, C. C. Chen and J. Y. Fang, Front. Chem., 2020, 8, 286.

28. H. Zazo, C. I. Colino and J. M. Lanao, J. Control. Release, 2016, 224, 86-102.

29. I. P. Chang, K. C. Hwang, J.-a. A. Ho, C.-C. Lin, R. J. R. Hwu and J.-C. Horng, Langmuir, 2010, 26, 3685-3689.

30. O. Faklaris, D. Garrot, V. Joshi, J.-P. Boudou, T. Sauvage, P. Curmi and F. Treussart, J. Eur. Opt. Soc.-Rapid Publ., 2009, 4, 09035.

31. S. Kühn, C. Hettich, C. Schmitt, J.-P. Poizat and V. Sandoghdar, J. Microsc., 2001, 202, 2-6.

32. J. H. Li, R. Yu and X. Yang, Appl. Phys. B: Lasers Opt., 2013, 111, 65-73.

33. P. Reineck, D. W. M. Lau, E. R. Wilson, K. Fox, M. R. Field, C. Deeleepojananan, V. N. Mochalin and B. C. Gibson, ACS Nano, 2017, 11, 10924-10934.

34. H. Yokota, Biochim. Biophys. Acta, Gen. Subj., 2020, 1864, 129362.

35. K. Turcheniuk and V. N. Mochalin, Nanotechnology, 2017, 28, 252001.

36. S. Szunerits, A. Barras and R. Boukherroub, Int. J. Environ. Res. Public Health, 2016, 13, 413413.

37. J. Jira, B. Rezek, V. Kriha, A. Artemenko, I. Matolinova, V. Skakalova, P. Stenclova and A. Kromka, Nanomaterials, 2018, 8, 140.

38. A. Chatterjee, E. Perevedentseva, M. Jani, C. Y. Cheng, Y. S. Ye, P. H. Chung and C. L. Cheng, J. Biomed. Opt., 2015, 20, 051014.

39. S. Pacelli, F. Acosta, A. R. Chakravarti, S. G. Samanta, J. Whitlow, S. Modaresi, R. P. H. Ahmed, J. Rajasingh and A. Paul, Acta Biomater., 2017, 58, 479-491.

40. A. Sigaeva, A. Morita, S. R. Hemelaar and R. Schirhagl, Nanoscale, 2019, 11, 17357-17367.

41. Y. Yu, X. Yang, M. Liu, M. Nishikawa, T. Tei and E. Miyako, Nanoscale Adv., 2019, 1, 3406-3412.

42. W. Long, H. Ouyang, W. M. Wan, W. F. Yan, C. Q. Zhou, H. Y. Huang, M. Y. Liu, X. Y. Zhang, Y. L. Feng and Y. Wei, Mater. Sci. Eng., C, 2020, 108, 110413.

43. Y. Dong, R. X. Cao, Y. Q. Li, Z. Q. Wang, L. Li and L. Tian, RSC Adv., 2015, 5, 82711-82716.

44. $\quad$ S. G. Wei, L. Li, X. B. Du and Y. Q. Li, J. Mater. Chem. B, 2019, 7, 3390-3402.

45. V. S. Madamsetty, A. Sharma, M. Toma, S. Samaniego, A. Gallud, E. F. Wang, K. Pal, D. Mukhopadhyay and B. Fadeel, Nanomedicine, 2019, 18, 112-121.

46. S. R. Qin, Q. Zhao, Z. G. Cheng, D. X. Zhang, K. K. Zhang, L. X. Su, H. J. Fan, Y. H. Wang and C. X. Shan, Diamond Relat. Mater., 2019, 91, 173-182.

47. S. Garg, A. Garg, N. K. Sahu and A. K. Yadav, Diamond Relat. Mater., 2019, 94, 172-185.

48. A. Hekmat, F. Salavati and S. H. Tackallou, Protein J., 2020, DOI: 10.1007/s10930-020-09882-4, 268-283.

49. D. Maziukiewicz, B. F. Grzeskowiak, E. Coy, S. Jurga and R. Mrowczynski, Biomimetics, 2019, 4, 3.

50. R. Matshitse, B. P. Ngoy, M. Managa, J. Mack and T. Nyokong, Photodiagn. Photodyn. Ther., 2019, 26, 101-110. 
51. R. Matshitse, M. Managa and T. Nyokong, Diamond Relat. Mater., 2020, 101, 107617.

52. C. Mauriello-Jimenez, N. Z. Knezevic, Y. G. Rubio, S. Szunerits, R. Boukherroub, F. Teodorescu, J. G. Croissant, O. Hocine, M. Seric, L. Raehm, V. Stojanovic, D. Aggad, M. Maynadier, M. Garcia, M. Gary-Bobo and J. O. Durand, J. Mater. Chem. B, 2016, 4, 5803-5808.

53. T. K. Ryu, S. W. Baek, R. H. Kang, K. Y. Jeong, D. R. Jun and S. W. Choi, J. Control. Release, 2018, 270, 237-245.

54. J. D. Dong, R. M. Jiang, H. Y. Huang, J. Y. Chen, J. W. Tian, F. J. Deng, Y. F. Dai, Y. Q. Wen, X. Y. Zhang and Y. Wei, Mater. Sci. Eng., C, 2020, 106, 110297.

55. E. Perevedentseva, N. Ali, A. Karmenyan, I. Skovorodkin, R. Prunskaite-Hyyrylainen, S. Vainio, C. L. Cheng and M. Kinnunen, Materials, 2019, 12, 3762.

56. N. Nunn, M. D'Amora, N. Prabhakar, A. M. Panich, N. Froumin, M. D. Torelli, I. Vlasov, P. Reineck, B. Gibson, J. M. Rosenholm, S. Giordani and O. Shenderova, Methods Appl. Fluoresc., 2018, 6, 035010.

57. P. Rouhani, N. Govindaraju, J. K. Iyer, R. Kaul, A. Kaul and R. N. Singh, Mater. Sci. Eng., C, 2016, 63, 323-332.

58. P. Rouhani and R. N. Singh, J. Nanosci. Nanotechnol., 2020, 20, 3957-3970.

59. B. M. Chang, L. Pan, H. H. Lin and H. C. Chang, Sci. Rep., 2019, 9, 13164.

60. A. Shirani, Q. C. Hu, Y. C. Su, T. Joy, D. H. Zhu and D. Berman, ACS Appl. Mater. \& Interfaces, 2019, 11, 43500-43508.

61. U. Mangal, J. Y. Kim, J. Y. Seo, J. S. Kwon and S. H. Choi, Materials, 2019, 12, 3438.

62. J. M. Gutierrez, K. Conceicao, V. M. de Andrade, V. J. Trava-Airoldi and G. Capote, Surf. Coat. Technol., 2019, 375, 395-401.

63. S. Houshyar, G. S. Kumar, A. Rifai, N. Tran, R. Nayak, R. A. Shanks, R. Padhye, K. Fox and A. Bhattacharyya, Mater. Sci. Eng., C, 2019, 100, 378-387.

64. A. Selaru, D. M. Dragusin, E. Olaret, A. Serafim, D. Steinmuller-Nethl, E. Vasile, H. lovu, I. C. Stancu, M. Costache and S. Dinescu, Materials, 2019, 12, 2933.

65. K. A. Laptinskiy, H. Kettiger, O. A. Shenderova, S. A. Burikov, J. M. Rosenholm and T. A. Dolenko, Nanodiamond based complexes for prolonged dexamethasone release, SPIE, 2019.

66. A. Pentecost, M. J. Kim, S. Jeon, Y. J. Ko, I. C. Kwon, Y. Gogotsi, K. Kim and K. L. Spiller, Regener. Biomater., 2019, 6, 163-174.

67. L. Fusco, E. Avitabile, V. Armuzza, M. Orecchioni, A. Istif, D. Bedognetti, T. Da Ros and L. G. Delogu, Carbon, 2020, 160, 390-404.

68. Y. Gou, Z. L. Zhang, D. Y. Li, L. Zhao, M. L. Cai, Z. W. Sun, Y. P. Li, Y. Zhang, H. Khan, H. B. Sun, T. Wang, H. Liang and F. Yang, Drug Delivery, 2018, 25, 321-329.

69. J. G. Croissant, C. Mauriello-Jimenez, M. Maynadier, X. Cattoen, M. W. C. Man, L. Raehm, O. Mongin, M. Blanchard-Desce, M. Garcia, M. Gary-Bobo, P. Maillard and J. O. Durand, Chem. Commun., 2015, 51, 12324-12327.

70. J. Mei, N. L. C. Leung, R. T. K. Kwok, J. W. Y. Lam and B. Z. Tang, Chem. Rev., 2015, 115, 1171811940.

71. E. Kłodzińska, M. Szumski, E. Dziubakiewicz, K. Hrynkiewicz, E. Skwarek, W. Janusz and B. Buszewski, Electrophoresis, 2010, 31, 1590-1596.

72. S. Halder, K. K. Yadav, R. Sarkar, S. Mukherjee, P. Saha, S. Haldar, S. Karmakar and T. Sen, SpringerPlus, 2015, 4, 672.

73. H.-J. Kim, K. Zhang, L. Moore and D. Ho, ACS Nano, 2014, 8, 2998-3005.

74. M. Gu, T. B. Toh, L. Hooi, J. J. Lim, X. Zhang and E. K.-H. Chow, ACS Appl. Mater. \& Interfaces, 2019, 11, 45427-45441.

75. H. Li, M. Ma, J. Zhang, W. Hou, H. Chen, D. Zeng and Z. Wang, ACS Appl. Mater. \& Interfaces, 2019, 11, 20341-20349.

76. K. Solarska-Ściuk and H. Kleszczyńska, Acta Pol. Pharm., 2019, 76, 779-796.

77. V. Vaijayanthimala, D. K. Lee, S. V. Kim, A. Yen, N. Tsai, D. Ho, H. C. Chang and O. Shenderova, Expert Opin. Drug Delivery, 2015, 12, 735-749. 
78. D.-K. Lee, T. Kee, Z. Liang, D. Hsiou, D. Miya, B. Wu, E. Osawa, E. K.-H. Chow, E. C. Sung, M. K. Kang and D. Ho, Proc. Natl. Acad. Sci., 2017, 114, E9445-E9454.

79. O. Shenderova and N. Nunn, in Nanodiamonds: Advanced Material Analysis, Properties and Applications, ed. J.-C. Arnault, Elsevier, Amsterdam, Micro and Nano Technologies edn., 2017, ch. 2, pp. 25-56.

80. J. Whitlow, S. Pacelli and A. Paul, J. Control. Release, 2017, 261, 62-86. 